\title{
The Habitual Tendencies Questionnaire: A Tool for Psychometric Individual Differences Research
}

\author{
Smriti Ramakrishnan ${ }^{\mathrm{a}}$,Trevor W Robbins ${ }^{\mathrm{b}, \mathrm{c}}$, \& Leor Zmigrod ${ }^{\mathrm{b}, \mathrm{c}}$
}

\begin{abstract}
Affiliations
${ }^{\text {aS }}$ chool of Clinical Medicine, University of Cambridge, United Kingdom

${ }^{b}$ Department of Psychology, University of Cambridge, United Kingdom

${ }^{\mathrm{c} B e h a v i o u r a l}$ and Clinical Neuroscience Institute, University of Cambridge, United Kingdom
\end{abstract}

\section{Corresponding author}

Dr Leor Zmigrod, 1z343@cam.ac.uk.

This manuscript is currently under peer review.

\begin{abstract}
Habits are automatic responses to learned stimuli or contextual cues that are insensitive to goals. While habits may allow for automated behaviours that increase efficiency in our daily lives, an over-reliance on habits has been suggested to contribute to disorders such as obsessive-compulsive disorder (OCD). There are currently few established measures of individual differences in habitual tendencies. To fill this gap, the present study generated and validated a novel 11-item scale, the Habitual Tendencies Questionnaire (HTQ), to measure individual differences in habitual tendencies in the general population. In Study 1, factor analysis revealed three underlying subcomponents of the HTQ: Compulsivity, Preference for Regularity, and Aversion to Novelty, with Compulsivity showing the strongest association with subclinical OCD symptomatology. Study 2 validated the HTQ and replicated the findings of Study 1 in a larger sample, and explored relationships with other personality traits. The results emphasize the importance of measuring individual variation in habitual thinking styles,
\end{abstract}


illustrating that different facets of habitual tendencies may contribute to diverse behavioural and clinical outcomes. The present investigation provides a new, reliable way of measuring habitual tendencies and has important implications for future explorations into the nature of individual differences from a dimensional perspective to psychiatry.

\section{Keywords}

Habits; Obsessive-Compulsive; Habitual Tendencies Questionnaire; Individual Differences 


\section{Introduction}

Living creatures are "bundles of habits" observed William James (1890, p.3), and indeed humans quickly learn to repeat and perpetuate responses when faced with recurring contextual cues. Nonetheless, not all individuals are equally "habitual", with some individuals exhibiting strong tendencies towards routine and compulsivity in their daily lives, while others naturally reject routine and repetition and opt for more varied change instead. Individual differences in habitual tendencies may underpin or reflect a large range of cognitive dispositions and behavioural outcomes, and so developing an effective questionnaire that taps into such individual differences is valuable across the psychological sciences.

Verplanken and Aarts (1999, p.104) defined habits as "learned sequences of acts that have become automatic responses to specific cues, and are functional in obtaining certain goals or end-states". However, this definition does not take into account other aspects of habits, such as compulsive and addictive behaviours, which are not necessarily goal-directed. More recent definitions of habits include "automatic behavioural responses to environmental cues, thought to develop through repetition of behaviour in consistent contexts" (Lally \& Gardner, 2013, p.137) and "representations of stimulus-response links that do not refer to goals, and are in a sense directly elicited by the environmental states or stimuli or contexts" (Robbins and Costa, 2017, p.1201). These suggest that habits are not goal-directed, but instead emphasise their stimulus-response nature. Indeed, it is now widely accepted that habitual behaviours are not mediated by goal pursuit (Wood \& Neal, 2007). Although a behaviour may originally have been motivated by goal pursuit, once it has been established as a habit, the goal is no longer needed to motivate the behaviour (Ersche et al., 2017).

Despite a long tradition of theorising about the nature of habit, from James to modern neuroscience, some have suggested that habit is an "empty construct". This is because many of these studies used past behavioural frequency as a measure of habit, and statistical 
relationships between past and future behaviours are ambiguous as they may be influenced by confounding variables that are not measured. However, Verplanken and Aarts (1999, p.102) argued against the notion of habit as an "empty construct". Instead, they suggested that different paradigms are needed in order to understand habits more fully, and that "habits are not only response programs, but may have far-reaching consequences for our cognitive functioning, for instance the way we perceive situations and process information". This emphasises the importance of studying habits, not only in themselves, but as indicators of cognitive functions and various personality traits. Habits can be beneficial by improving efficiency in our daily lives and increasing the availability of cortical processing capacity for novel, important situations (Robbins \& Costa, 2017). However, excessive reliance on habits can be detrimental to behavioural plasticity, and can contribute to the development of disorders of compulsivity (Gillan et al., 2016) such as obsessive-compulsive disorder (OCD; Gillan et al., 2015) and substance dependence (Everitt \& Robbins, 2016; Sjoerds et al., 2013).

In order to study habits, we must be able to reliably measure them. Therefore, the current investigation aimed to develop a validated, representative scale to measure individual variation in dependence on habits: the Habitual Tendencies Questionnaire (HTQ). In order to create the HTQ, we first conducted a thorough literature review of existing measures of habits and sought to evaluate their strengths and weaknesses. Two established scales measuring habits are the Self-Report Habit Index (Verplanken and Orbell, 2003) and the Creature of Habit Scale (Ersche et al., 2017). Verplanken and Orbell (2003, p.1314) developed the Self-Report Habit Index (SRHI), a twelve-item self-report index of habit strength, to reflect their argument that "habit is a psychological construct, rather than simply past behavioral frequency". Consequently, the SRHI aims to focus on features of habit such as a history of repetition, automaticity, and expressing one's identity, rather than on past behavioural frequency. In this scale, a particular behaviour, $\mathrm{X}$, is followed by 12 different options from which the participant 
must choose, such as "...I do frequently" or “...I do without thinking”. Nonetheless, the behaviours used for $\mathrm{X}$ in two out of four experiments in this study related to modes of transport, which may not be representative of an individual's dependence on habits in general. In another experiment, participants were asked to list some of their own habits, which they performed either daily or weekly. Although using habits unique to each participant ensured that the behaviours were relatable, this is a very time-consuming method, and thus would not be feasible to use in many research designs. Furthermore, these behaviours were assumed to be habitual based on their frequency and regularity, which seems to contradict the authors' argument that habit is not exclusively past behavioural frequency. In the present study, we concurred with Verplanken and Orbell's view that habit is a psychological construct that includes behaviours with a history of repetition, automaticity and expressing one's identity. Here, we take this one step further, and consider habits as also encompassing attitudes, beliefs and thinking styles. Therefore, we set out to develop an easy-to-administer tool to measure all of these aspects of habits, with items that are representative of habits in general, and as universally relatable as possible.

Another recent scale developed to measure habits is the Creature of Habit Scale, COHS (Ersche et al., 2017). Two main subscales were identified by the authors: routine and automaticity, reflecting two different features of habits. A potential limitation of the COHS is that more than half of the items are food-related, and these items make up the majority of the automaticity subscale. It is possible that an individual's food-related habits are not representative of their habitual tendencies in general, as many people are habitual in their eating behaviours (van't Riet et al., 2011), but not necessarily in other aspects of their daily lives. Therefore, we avoided including food-related items in the HTQ, with the exception of those that reflected more general habitual tendencies. 
To the best of our knowledge, no scale exists that measures behaviours, attitudes, beliefs and thinking styles relating to habits. We considered these four dimensions as follows: behaviour as reflecting individual differences in dependence on routines or habits in daily life, attitude as the desire for structure or order in life (which might make individuals routine-prone), belief as beliefs about the value of having routines or habits (not about the personal self but in general), and thinking style in terms of a compulsive thinking style that is susceptible to habitual or non-goal directed behaviour. All these dimensions may play major roles in the development and maintenance of habits, as well as potentially contributing to associations between habits and other aspects of cognition such as personality traits, psychopathology and cognitive functions. Therefore, the HTQ aims to encompass all of these aspects of habits.

Our criteria for the HTQ were such that it should consist of items that are conceptually representative of the habitual tendencies construct in general, as per our definitions and descriptions; be relatable to everyday life for individuals across the general population; and be quick and easy to administer. Study 1 sought to create a new scale to measure individual differences in habitual tendencies, the Habitual Tendencies Questionnaire (HTQ), and Study 2 aimed to validate and replicate the HTQ in a larger sample, and to explore the relationships between the HTQ and the Creature of Habit Scale (Ersche et al., 2017). Finally, we analysed the results of Study 1 and Study 2 together in order to evaluate the nature of the individual differences in habitual tendencies in the larger combined participant sample.

\section{Study 1}

In order to construct the HTQ, we conducted an extensive literature review of existing measures in order to identify potential items that could be used and adapted to create a multidimensional self-report scale of habitual tendencies in healthy individuals. We consulted the following theoretically-adjacent constructs: 
- Intolerance of uncertainty or ambiguity, defined as "the tendency to perceive (i.e. interpret) ambiguous situations as sources of threat" (Budner, 1962, p.29-30), with ambiguous situations being described as those "which cannot be adequately structured or categorised by the individual because of the lack of sufficient cues". FrenkelBrunswik, cited in Bar-Tal (1994), suggested that intolerance of ambiguity is a preference for familiarity, symmetry, definiteness, and regularity, all of which seem to reflect qualities of habits.

- Need for cognitive closure, defined as "an answer on a given topic, any answer ... compared to confusion and ambiguity" (Kruglanski, 1990, p.337).

- Need for cognitive structure, defined as "the desire for clear and firm knowledge concerning a given topic, as opposed to ambiguity, doubt, or confusion” (Bar-Tal, 1994, p.46).

- Routines, defined as "familiar action patterns that involve regularity, which are likely to be performed on a daily basis" (Ersche et al., 2017, p.77)

- Automaticity, with automatic actions being defined as those that are "initiated by environmental cues without a deliberate intention, and they may even continue without the involvement of conscious control" (Ersche et al., 2017, p.78)

- Compulsivity, defined as "the tendency to repeat over and over a certain kind of behavior despite its inappropriateness, and to be unable to inhibit the behavior" (Bari and Robbins, 2013, p.52). Compulsivity has further been described as the "manifestation of an imbalance between the brain's goal-directed and habit-learning systems" (Gillan et al., 2016, p.828), and as "a maladaptive perseveration of behaviour" (Robbins et al., 2012, p.83), contributing to the use of habit as a model of compulsivity. All of the above constructs reflect different characteristics of habitual tendencies, and thus were included as keywords in our literature search. 


\section{Methods}

\section{Participants}

For Study 1, we recruited 165 participants, each of whom were paid $\$ 4.50$ for their participation in the study, through Amazon Mechanical Turk (MTurk) online platform, which is well established for obtaining general population samples (Cheung et al., 2017). Of these, $35(21.2 \%)$ were removed prior to data analysis due to failure of attention checks and repeat participation in the study identified via duplicated IP addresses. The 130 remaining participants consisted of $49 \%$ males, $50 \%$ females and $1 \%$ other, between the ages of 22 and $73(\mathrm{M}=$ 39.527, $\mathrm{SD}=12.120$ ). All participants were based in the United States of America. The sample identified as $72 \%$ White, $11 \%$ Mixed ethnicity, $8 \%$ Black or African American, $6 \%$ Asian, $2 \%$ American Indian or Alaska Native, and 1\% Hispanic/Latino. The highest levels of educational attainment of the sample population were as follows: $1 \%$ had achieved less than a high school degree, $13 \%$ had graduated high school, $19 \%$ had completed some school but did not have a degree, $15 \%$ had completed a 2-year Associate degree in college, 38\% had completed a 4-year Bachelor's degree in college, $12 \%$ had a Master's degree, and 2\% had a Doctoral or Professional degree. Ethical approval for the study was obtained from the Department of Psychology Ethics Committee of the University of Cambridge. Electronic informed consent was obtained from all participants before beginning the survey, in line with the Declaration of Helsinki (1964), and participants were informed that they may terminate their participation in the study at any point.

\section{Scale development}

The development of the HTQ followed a rigorous process of item selection (see Figure 1 for flowchart of scale development). Following a thorough literature review, we selected a series of keywords relating to habits and used these to search for relevant existing scales in 
Google Scholar. These keywords were: "cognitive closure”, “cognition”, "uncertainty", "ambiguity", "cognitive structure", "habit*”, "routine*”, “automatic*”, "goal-directed", and "compulsiv*". We also used a citation search, in order to maximise the number of scales identified. We then pooled all the items from each of the scales found. 27 scales were identified, resulting in a total of 618 items. We used a process of elimination to narrow down the number of potential items for the HTQ. Firstly, the full versions of scales were removed, where validated shortened or revised versions existed, as were scales consisting entirely of items irrelevant to the HTQ. 19 scales then remained. Next, where factor loadings were available, items with factor loadings below 0.4 were removed, to ensure that the remaining items were representative, and following this, any duplicate items were removed in order to achieve nonredundancy. This resulted in a pool of 401 items. Finally, we selected 37 of these items for our scale. For each item, we considered its uniqueness; relevance to our four proposed aspects of the habitual tendencies construct; conceptual clarity; and applicability to current, everyday life. The HTQ aims to capture four distinct aspects of habits: behaviour, attitude, belief and thinking style. Therefore, as we selected items for our scale, we categorised each item into one of these four subscales, ensuring a minimum of 7 items per subscale (see Supplementary Materials). 


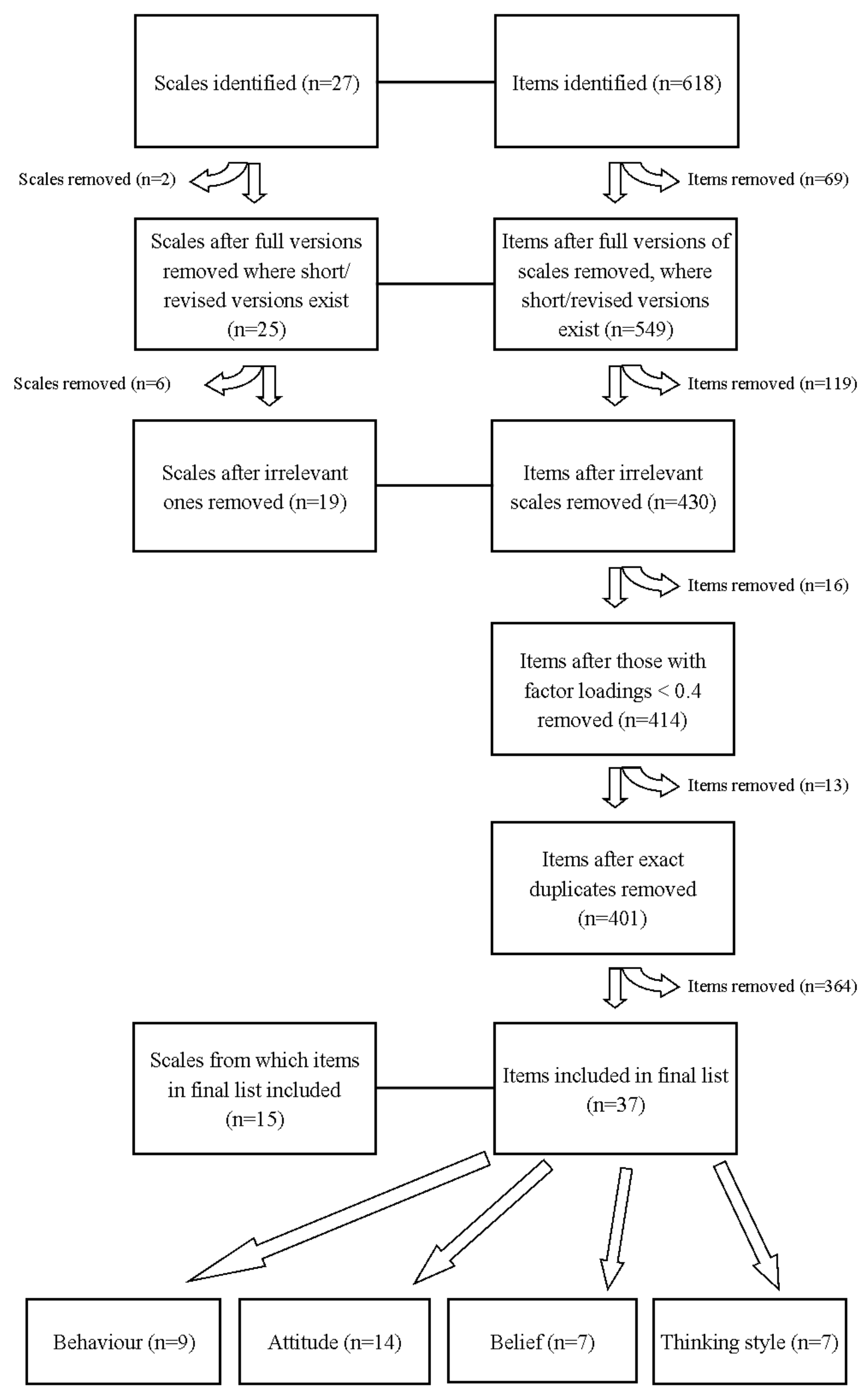

Figure 1. Flowchart of scale development. 


\section{Measures}

We administered the 37-item HTQ scale, along with the additional measures and cognitive tasks, in the form of an electronic survey. Items from the HTQ were rated on 7-point Likert scales ranging from "Strongly disagree" to "Strongly agree" and were randomised across factor categories. In order to measure subclinical OCD symptomatology, we used the 18 -item revised version of the Obsessive-Compulsive Inventory, OCI (Foa et al., 2002), which was rated on 5-point Likert scales ranging from "Not at all" to "Extremely", and had a high Cronbach's $\alpha$ value of 0.954 . Example items included: "I repeatedly check doors, windows, drawers, etc." and "I frequently get nasty thoughts and have difficulty in getting rid of them". In order to measure intolerance of uncertainty, we used the 12-item short version of the Intolerance of Uncertainty Scale, IUS (Carleton et al., 2007), which was rated on 5-point Likert scales ranging from "Not at all characteristic of me" to "Entirely characteristic of me", and had a high Cronbach's $\alpha$ value of 0.912. Example items included "Unforeseen events upset me greatly" and "The smallest doubt can stop me from acting". In order to measure autismspectrum traits, we used the 10-item short version of the Autism Quotient, AQ-10 (Allison et al., 2012), which was rated on 4-point Likert scales ranging from "Definitely disagree" to “Definitely agree", and had an adequate Cronbach's $\alpha$ value of 0.684. Example items included "I often notice small sounds when others do not" and "I find it easy to work out what someone is thinking or feeling just by looking at their face". The survey also included two interspersed measures of attention to ensure that participants were concentrating on their responses to the questions ("I am paying attention to this survey. I strongly agree"). 


\section{Results}

All statistical analyses were conducted using JASP (Version 0.12.2; JASP Team, 2020), SPSS (Version 27.0; IBM Corp, 2020) and R Studio (RStudio Team, 2020).

The HTQ scores based on the 37-item version followed an approximately normal distribution according to the Shapiro-Wilk test $(p=0.955)$, with minimal skewness $(-0.090)$ and kurtosis (0.136), and Cronbach's $\alpha$ was calculated to be 0.903 , with a $95 \%$ confidence interval $[0.878,0.926]$.

\section{Factor analysis}

Factor analysis is a statistical dimensionality-reduction method for empirically identifying the structure underlying a variety of measurements (Thompson, 2007). Thompson further states that factor analysis is used for three main purposes: 1) "empirically creating a theory of structure", 2) "evaluating whether factored entities cluster in a theoretically expected way", and 3) "estimating latent variables scores (i.e., factor scores) that are then used in subsequent statistical analyses... in place of the measured factored entities". We used factor analysis for the second of these purposes, in order to validate the HTQ, and to create a shorter, revised version of the HTQ, consisting of the items most representative of the habitual tendencies construct.

Exploratory factor analysis (EFA) was carried out using maximum likelihood as the factor extraction method, as recommended by Costello and Osborne (2005) (see Supplementary Materials, Table S1 for factor loadings). We expected the different aspects of habits to be intercorrelated, and thus used oblique oblimin rotation with parallel analysis. Four factors were obtained, supported by the scree plot and path diagram. We then applied some a priori decision criteria (in line with past research, e.g. Krumrei-Mancuso et al., 2016), in order to select which items would be included in further analyses. These were as follows: items must 
have a minimum factor loading of 0.4 , which resulted in the removal of 9 items (HTQ11, HTQ12, HTQ13, HTQ17, HTQ 20, HTQ21, HTQ25, HTQ32 and HTQ34); and items must not cross-load onto their alternative factors above 0.3 , which resulted in the removal of a further 8 items (HTQ 3, HTQ5, HTQ14, HTQ15, HTQ22, HTQ23, HTQ29 and HTQ31). Exploratory factor analysis was then run again in order to avoid skew due to the removed items, and three factors were obtained (see Supplementary Materials, Table S2). One further item (HTQ2) was subsequently removed as its factor loading was below 0.4 , and thus it did not fulfil our inclusion criteria. A third EFA was then carried out, and the three-factor structure was maintained with 19 items.

Examination of the items in each of the three factors revealed that each factor reflected a distinct aspect of habitual tendencies. Factor 1 encompassed items related to compulsivity and very clearly reflected the thinking style dimension of habitual tendencies. Factor 2 encompassed items related to a preference for regularity and routines, mirroring the attitude dimension of habitual tendencies: desire for structure or order in life. Factor 3 encompassed items related to an aversion to new experiences or change, reflecting habitual behaviours.

\section{Item selection for a shortened scale}

In order to create an easy-to-administer scale, we sought to shorten it. As manifest in Figure 2, we decided to select up to 4 items per factor, choosing the items that loaded most strongly on those factors in the exploratory factor analysis. This resulted in the selection of 11 items, which were subjected to another EFA (see Table 1 and Supplementary Materials, Figure S1). As expected, three factors emerged, supported by the scree plot and path diagram (see Supplementary Materials, Figure S1), and all items continued to load onto the same factors as they had previously done. 


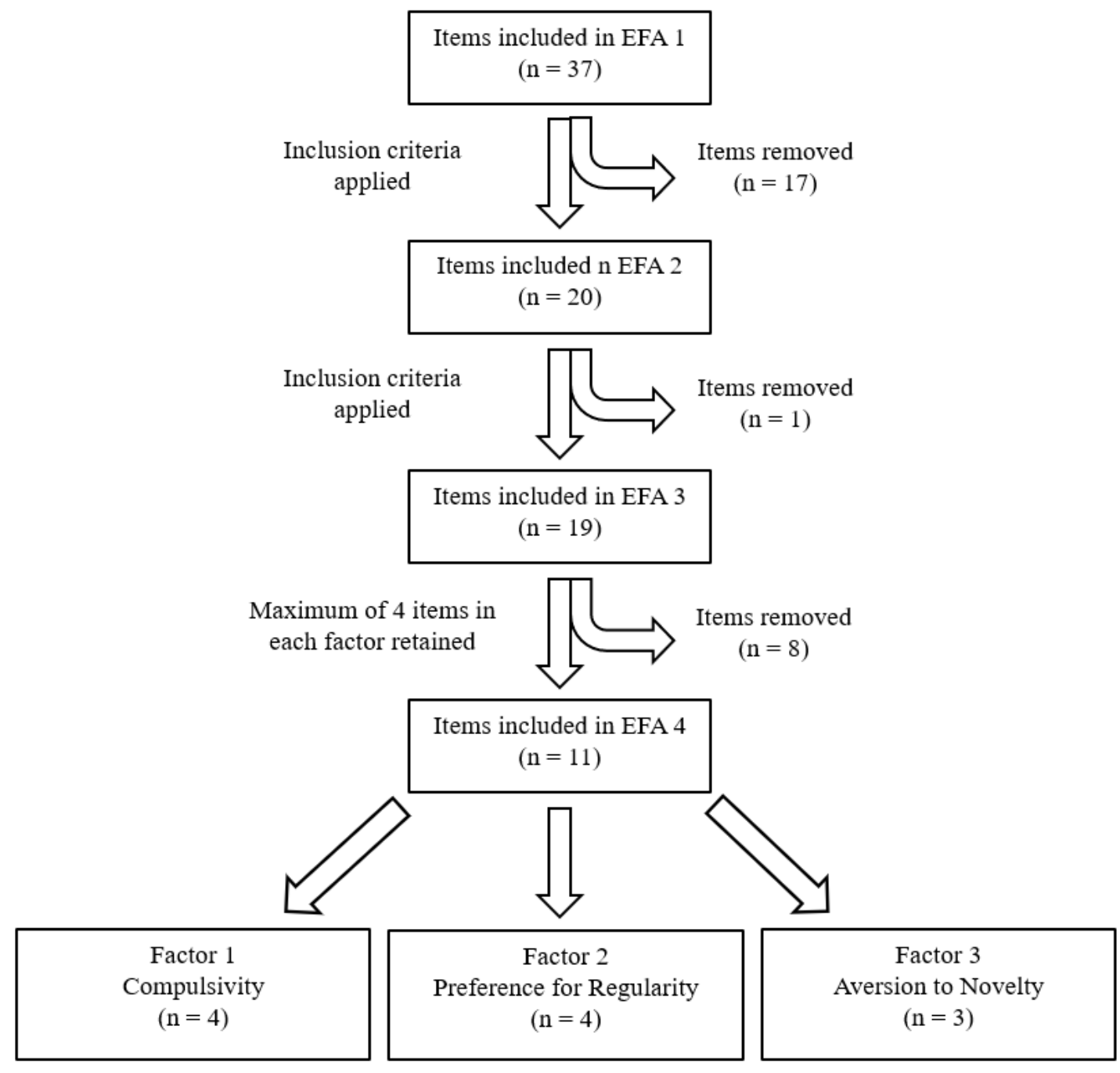

Figure 2. Flowchart of item selection for final 11-item Habitual Tendencies Questionnaire (HTQ). 
Table 1. Exploratory factor analysis of final 11-item Habitual Tendencies Questionnaire.

\begin{tabular}{|c|c|c|c|c|}
\hline \multirow[b]{2}{*}{ Items } & \multicolumn{3}{|c|}{ Component Loadings } & \multirow[b]{2}{*}{ Uniqueness } \\
\hline & Factor 1 & $\begin{array}{l}\text { Factor } \\
\quad 2\end{array}$ & $\begin{array}{l}\text { Factor } \\
\mathbf{3}\end{array}$ & \\
\hline HTQ 37: I tend to dwell on the same issues & 0.91 & -0.05 & 0.02 & 0.18 \\
\hline HTQ 36: I mentally fixate on certain issues and can't move on & $\mathbf{0 . 8 8}$ & 0.02 & -0.03 & 0.22 \\
\hline $\begin{array}{l}\text { HTQ 35: The same thoughts often keep going through my mind over and } \\
\text { over again }\end{array}$ & 0.84 & 0.00 & 0.06 & 0.27 \\
\hline $\begin{array}{l}\text { HTQ 33: I tend to repeat actions because I keep doubting that I have done } \\
\text { them properly }\end{array}$ & 0.59 & 0.10 & -0.17 & 0.63 \\
\hline HTQ 10: I like to have a regular, unchanging schedule & -0.02 & 0.70 & 0.10 & 0.46 \\
\hline HTQ 9: There is comfort in regularity & -0.10 & 0.67 & -0.06 & 0.58 \\
\hline HTQ 27: A good job has clear guidelines on what to do and how to do it & -0.01 & 0.67 & -0.09 & 0.59 \\
\hline HTQ 1: I hate it when my routines are disrupted & 0.14 & 0.68 & 0.10 & 0.43 \\
\hline HTQ 30: I look forward to new experiences R & 0.03 & 0.02 & 0.92 & 0.14 \\
\hline HTQ 26: Life is boring if you never take risks and always play it safe $R$ & -0.06 & 0.00 & 0.67 & 0.56 \\
\hline $\begin{array}{l}\text { HTQ 7: When eating at restaurants, I like to try new dishes rather than ones } \\
\text { I have tried before R }\end{array}$ & -0.04 & 0.02 & 0.54 & 0.71 \\
\hline Correlation with Factor 1 & 1.00 & & & \\
\hline Correlation with Factor 2 & 0.17 & 1.00 & & \\
\hline Correlation with Factor 3 & 0.13 & 0.33 & 1.00 & \\
\hline
\end{tabular}

$\mathrm{R}=$ reversed item

Descriptive statistics and reliability analysis were then carried out on the final HTQ scale (all subsequent mentions of the HTQ refer to this final, 11-item scale - see Appendix, 11Item Habitual Tendencies Questionnaire), as well as for each factor individually. The HTQ scores continued to follow a normal distribution according to the Shapiro-Wilk test $(p=0.369)$, with minimal skewness (-0.019) and kurtosis (-0.080), and the mean total score was 34.546 (maximum possible score $=66$, range $=9-55)$, with standard deviation 9.042 (see Figure 3 ) . For the 11-item scale, Cronbach's $\alpha$ was 0.764 , with 95\% confidence interval $[0.699,0.820]$. Cronbach's $\alpha$ values showed good reliability for each factor, or subscale. These were 0.878 for Compulsivity; 0.770 for Preference for Regularity; and 0.733 for Aversion to Novelty. 

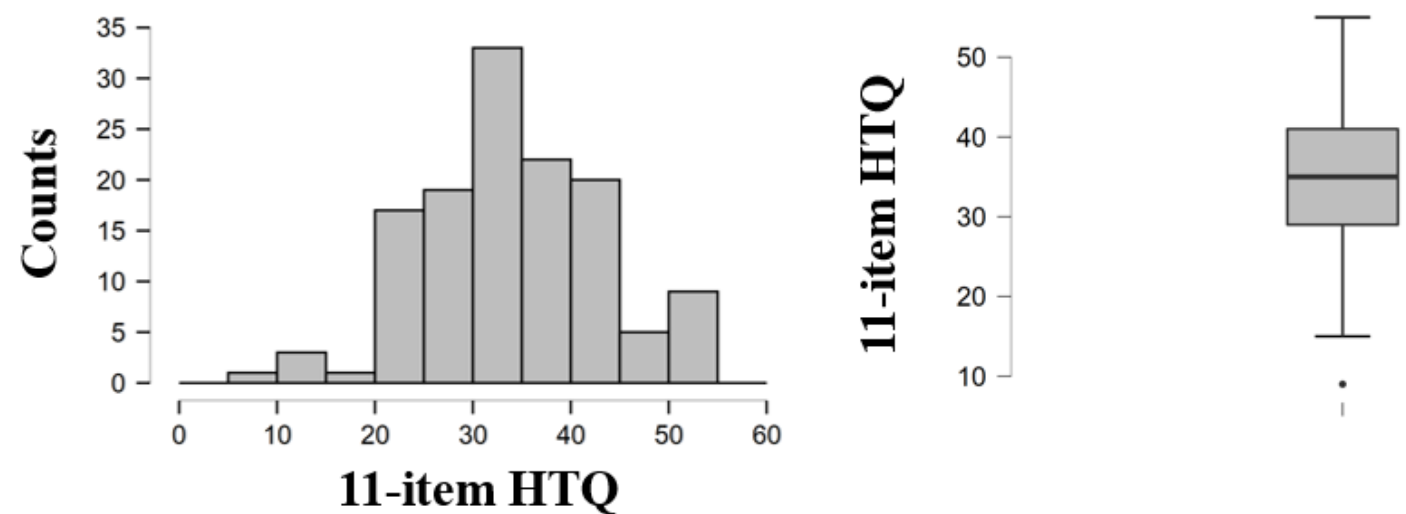

Figure 3. Descriptive statistics for final, 11-item Habitual Tendencies Questionnaire (HTQ): distribution plot and boxplot.

\section{Construct validity}

As evident in Table 2, all three HTQ subscales showed significant and strong positive correlations with the 11-item HTQ (with $\mathrm{r}$ values above 0.5 ), but only weak, mostly nonsignificant correlations with each other (with $r$ values less than 0.5 ). This corroborates the factor analysis in suggesting that each subscale is representative of a distinct aspect of the habitual tendencies construct.

In order to evaluate the relationships between the HTQ and relevant behavioural outcomes, we assessed the correlations between the Habitual Tendencies Questionnaire and subclinical OCD symptomatology. The Pearson's correlations for these variables were computed (see Table 2). As evident in Table 2, there was a significant positive correlation between the HTQ and OCI scales $(r=0.484, p<0.001)$. Within the three subscales of the HTQ, the Compulsivity subscale contributed the most to this association (see Table 2 and Figure 4), as it showed the strongest correlation with the OCI $(r=0.598, p<0.001)$, whereas the Preference for Regularity and Aversion to Novelty subscales were not significantly correlated with the OCI. The Pearson's $r$ effect sizes of 0.484 and 0.598 are relatively large, as per the individual differences research guidelines set out by Gignac and Szodorai (2016). 
To complement the Pearson's correlations, we also examined the Bayes Factors (see Table 2), which quantify the evidential strength in favour of a significant correlation given the present data $\left(\mathrm{H}_{1}\right.$, the alternative hypothesis), or in favour of no significant correlation given the present data $\left(\mathrm{H}_{0}\right.$, the null hypothesis). In line with the guidelines by Wagenmakers and colleagues (2018), a Bayes Factor $\left(\mathrm{BF}_{10}\right)$ above 100 indicates "extreme evidence" for $\mathrm{H}_{1}$ (significant correlation). Here we found that the relationship between HTQ Compulsivity and the OCI possesses an extremely large Bayes Factor of $1.474 \times 10^{11}$ (see Table 2), indicating that the observed data is $1.474 \times 10^{11}$ times more likely under $\mathrm{H}_{1}$ than $\mathrm{H}_{0}$. See Supplementary Materials for analysis of the associations of the HTQ with intolerance of uncertainty and autism spectrum traits.

Table 2. Correlation matrix of the Habitual Tendencies Questionnaire and OCD traits, including Pearson's correlations and Bayes Factors.

\begin{tabular}{|c|c|c|c|c|c|}
\hline & & HTQ & $\begin{array}{c}\text { HTQ } \\
\text { Compulsivity }\end{array}$ & $\begin{array}{c}\text { HTQ } \\
\text { Regularity }\end{array}$ & $\begin{array}{l}\text { HTQ Aversion } \\
\text { to Novelty }\end{array}$ \\
\hline \multirow[t]{2}{*}{ HTQ } & $\begin{array}{l}\text { Pearson's } \\
\mathrm{r}\end{array}$ & - & & & \\
\hline & $\mathrm{BF}_{10}$ & - & & & \\
\hline \multirow[t]{2}{*}{$\begin{array}{l}\text { HTQ } \\
\text { Compulsivity }\end{array}$} & $\begin{array}{l}\text { Pearson's } \\
\mathrm{r}\end{array}$ & $0.728 * * *$ & - & & \\
\hline & $\mathrm{BF}_{10}$ & $4.897 \times 10^{19}$ & - & & \\
\hline \multirow[t]{2}{*}{ HTQ Regularity } & $\begin{array}{l}\text { Pearson's } \\
\text { r }\end{array}$ & $0.672 * * *$ & 0.161 & - & \\
\hline & $\mathrm{BF}_{10}$ & $2.863 \times 10^{15}$ & 0.573 & - & \\
\hline \multirow[t]{2}{*}{$\begin{array}{l}\text { HTQ Aversion } \\
\text { to Novelty }\end{array}$} & $\begin{array}{l}\text { Pearson's } \\
\mathrm{r}\end{array}$ & $0.577 * * *$ & 0.065 & $0.278 * *$ & - \\
\hline & $\mathrm{BF}_{10}$ & $1.335 \times 10^{10}$ & 0.143 & 17.309 & - \\
\hline \multirow[t]{2}{*}{ OCI } & $\begin{array}{l}\text { Pearson's } \\
\mathrm{r}\end{array}$ & $0.484 * * *$ & $0.598 * * *$ & 0.146 & 0.103 \\
\hline & $\mathrm{BF}_{10}$ & $2.293 \times 10^{6}$ & $1.474 \times 10^{11}$ & 0.425 & 0.215 \\
\hline
\end{tabular}

$* p<0.05, * * p<0.01, * * * p<0.001 ; \mathrm{BF}<3=$ Anecdotal evidence; $\mathrm{BF}<10=$ Moderate evidence; $\mathrm{BF}<30=$ Strong evidence; $\mathrm{BF}<100=$ Very strong evidence; $\mathrm{BF}>100=$ Extremely strong evidence. HTQ = Habitual Tendencies Questionnaire. $\mathrm{OCI}=$ Obsessive-Compulsive Inventory. 


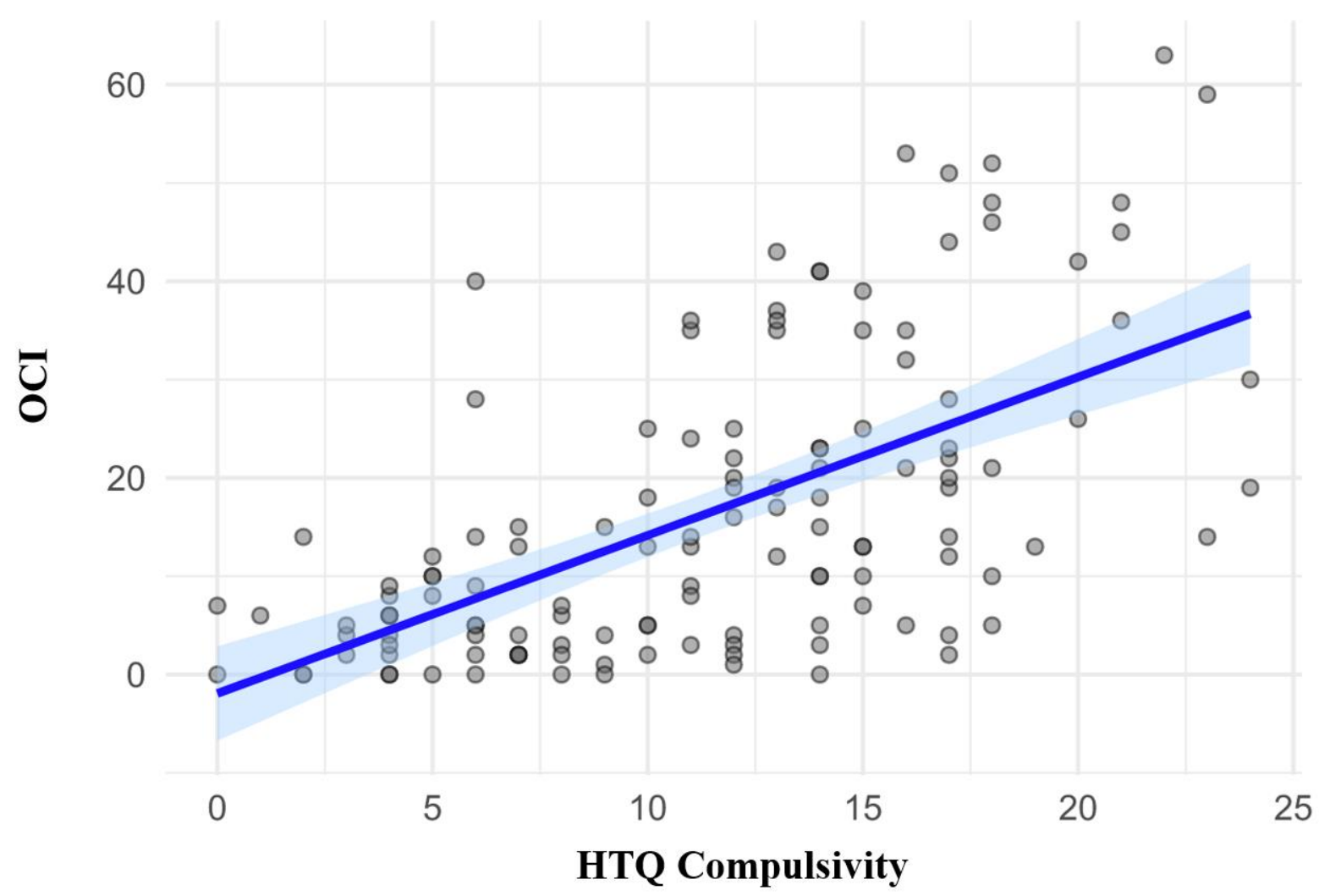

Figure 4. Scatter plot showing correlations between the Obsessive-Compulsive Inventory (OCI) and the Compulsivity subscale of the Habitual Tendencies Questionnaire (HTQ).

We then conducted a two-step hierarchical linear regression with the three subscales of the HTQ as predictors of subclinical OCD symptomatology, and age, gender and educational attainment as covariates. Of the demographic variables, only age was a significant predictor of subclinical OCD symptomatology $(\beta=-0.233, t(127)=-2.616, p=0.010)$, and of the three HTQ subscales, only HTQ Compulsivity emerged as a significant predictor of subclinical OCD symptomatology $(\beta=0.546, t(127)=7.385, p<0.001)$. The demographic variables explained $6.5 \%$ of the variance in subclinical OCD symptomatology $\left(R^{2}=0.065, F(3,124)=2.853, p=\right.$ 0.040), but addition of the three subscales of the HTQ in step 2 increased the $R^{2}$ term to 0.386 , accounting for a further $32.1 \%$ of the variance in subclinical OCD symptomatology $\left(R^{2}=\right.$ $0.386, F(3,121)=12.704, p<0.001)$. 


\section{Interim Discussion}

Study 1 has developed and validated a reliable, representative 11-item scale to measure individual differences in habitual tendencies in the general population, the Habitual Tendencies Questionnaire (HTQ). A total of 618 items from 27 existing scales were pooled through keyword and citation searches. Item selection took place through a process of elimination using a priori decision criteria, by considering factor loadings, non-redundancy, relevance to our four proposed aspects of the habitual tendencies construct, conceptual clarity, and applicability to current everyday life (see Figure 1). Exploratory factor analysis (EFA) resulted in the subdivision of the HTQ into 3 subscales, namely Compulsivity, Preference for Regularity and Aversion to Novelty (see Table 1 and Supplementary Materials, Tables S1 and S2). The HTQ as a whole encompassed the four aspects of habits we originally proposed: behaviour, attitude, belief and thinking style, highlighting that habits are more than merely past behavioural frequency (Verplanken and Orbell, 2003). However, although the three subscales obtained after factor analysis represented three distinct aspects of the habitual tendencies construct, these subscales differed somewhat from our four originally-proposed theoretical aspects (see Supplementary Materials, Extended 37-Item Habitual Tendencies Questionnaire). The clustering of items into the three distinct HTQ subscales provides a new way of dividing the habitual tendencies construct into its component parts, and allows the different aspects of habits to be studied separately. The construct validity of the HTQ was then demonstrated by exploring the Pearson's correlations and Bayes factors of the relationships between the HTQ, its three subscales, and existing measures of subclinical traits of clinical disorders related to maladaptive habits. Most notably, significant, strong positive correlations were found between HTQ Compulsivity and subclinical OCD symptomatology (as measured by the OCI). These findings suggest that the HTQ as a whole is representative of a range of different habitual tendencies, and its individual subscales may be used to explore the variable ways in which habits are 
distributed across different subclinical traits of clinical disorders. For example, the relationship between HTQ Compulsivity and the OCI implies that thinking style, rather than other features such as behaviour or attitudes towards the value of habits, is specifically related to subclinical OCD symptomatology. Hierarchical regression demonstrated that the three subscales of the HTQ explain a significant proportion of the variance in subclinical OCD symptomatology, and furthermore, revealed HTQ Compulsivity to be a significant predictor of subclinical OCD symptomatology. As such, the HTQ may be used as a validated measure of individual differences in habitual tendencies, and its subscales may have an important role in predicting subclinical traits in the general population.

\section{Study 2}

Study 1 developed the HTQ, and examined its relationships with subclinical OCD symptomatology in an exploratory way, demonstrating that its Compulsivity subscale acts as a predictor of OCD traits in a sample of the general population. In order to replicate and extend the findings of Study 1, we conducted a second study. Study 2 aimed to reproduce the positive association between HTQ Compulsivity and OCD traits found in Study 1, and furthermore, to examine how the HTQ relates to a recent measure of habitual tendencies, the Creature of Habit Scale, COHS (Ersche et al., 2017), in order to determine whether the HTQ is representative of the habitual tendencies construct. The aims of Study 2 were as follows: (1) to replicate the three-factor structure of the HTQ obtained in study 1 in a larger, independent sample; (2) to replicate the relationship between the HTQ and subclinical OCD symptomatology (as measured by the OCI); and (3) to explore associations between the HTQ and a recent measure of habitual tendencies, the Creature of Habit Scale (Ersche et al., 2017). 
Furthermore, Study 2 was preregistered on the Open Science Framework at the following link: https://osf.io/3ag79/?view_only=0e0478eb848b477180d25e8b175edad9. Some changes were made to Study 1 after the preregistration, namely that the number of items in the Habitual Tendencies Questionnaire (HTQ) was reduced from 20 to 11, in order to create an even shorter scale, resulting in a three-factor structure rather than a four-factor structure. In Study 2, we did not analyse the data for cognitive flexibility, binge eating, alcohol addiction, smoking habits or apathy in relation to the HTQ, as it was beyond the scope of the present paper.

\section{Methods}

\section{Participants}

In order to collect a well-powered participant pool, we pre-registered a power analysis that would allow us to evaluate the relationship between habitual tendencies and relevant behavioural outcomes. In order to estimate the expected effect sizes, we relied on previous work conducted by Ersche and colleagues (2017) on associations between habitual tendencies and OCD symptomatology. Specifically, Ersche and colleagues (2017) found a correlation of $r=0.265$ between the Routine subscale of the COHS and scores on the OCI. The power analysis indicated that a sample of 287 would be needed to detect an equivalent effect size $(\alpha=$ 0.05 , power $=0.90, r=0.265)$. We oversampled by $34.8 \%$ (98 participants) to have a total sample size of 385 due to the high prevalence of repeated IP addresses and bot responses in our sample. Each participant was paid $\$ 4.50$ for their participation in the study, through Amazon Mechanical Turk (MTurk) online platform. Of these, 126 (32.7\%) were removed prior to data analysis in line with guidance from Meade and Craig (2012) due to: failure of one or both attention checks $(n=28)$, being identified as a bot via repeated answers in an open-answer feature of the survey $(n=62)$, poor English proficiency identified by lack of understanding 
through irrelevant or incoherent answers to other features of the survey $(n=25)$, repeat participation in the study identified via duplicated IP addresses $(n=8)$, and finally one or more missing answers on the HTQ $(n=3)$. The 259 remaining participants consisted of $56 \%$ males, $43 \%$ females and $1 \%$ other/unspecified, between the ages of 19 and $73(\mathrm{M}=37.372, \mathrm{SD}=$ 11.280). All participants were based in the United States of America. The sample identified as 68.3\% White, $13.5 \%$ Black or African American, 5.8\% Mixed ethnicity, 4.6\% Asian, 4.6\% Hispanic/Latino, $1.2 \%$ American Indian or Alaska Native, $0.4 \%$ Native American/Pacific Islander, $1.2 \%$ other, $0.4 \%$ unspecified. The highest levels of educational attainment of the sample population were as follows: $0.4 \%$ had achieved less than a high school degree, $13.1 \%$ had graduated high school, $22.0 \%$ had completed some school but did not have a degree, $13.9 \%$ had completed a 2-year Associate degree in college, 43.2\% had completed a 4-year Bachelor's degree in college, $6.6 \%$ had a Master's degree, and $0.8 \%$ had a Doctoral or Professional degree. Ethical approval for the study was obtained from the Department of Psychology Ethics Committee of the University of Cambridge. Electronic informed consent was obtained from all participants before beginning the survey, in line with the Declaration of Helsinki (1964), and participants were informed that they may terminate their participation in the study at any point.

\section{Measures}

We administered the 11-item HTQ rated on 7-point Likert scales ranging from "Strongly disagree" to "Strongly agree", along with the additional measures and cognitive tasks, in the form of an electronic survey hosted by Qualtrics Survey Software. As in Study 1, these consisted of the revised OCI (Foa et al., 2002), which had a high Cronbach's $\alpha$ value of 0.944 as well as the Creature of Habit Scale (Ersche et al., 2017), which had a high Cronbach's $\alpha$ value of 0.902 . The survey also included two interspersed attention checks, as in Study 1. 


\section{Results}

\section{Replicating the Scale Structure}

As shown in Figure 5, the HTQ scores followed an approximately normal distribution according to the Shapiro-Wilk test $(p=0.323)$, with minimal skewness $(-0.124)$ and kurtosis (0.015). The mean total score on the HTQ was found to be 35.927 (maximum possible score $=$ 66 , range $=6-63$ ), with standard deviation 10.082, and a good Cronbach's $\alpha$ of 0.810 , with 95\% confidence interval $[0.774,0.843]$. Cronbach's $\alpha$ values for each of the subscales were 0.822 for Compulsivity, 0.777 for Preference for Regularity, and 0.694 for Aversion to Novelty. Next, we conducted a Confirmatory Factor Analysis (CFA), which provides indicators of model fit to help researchers decide whether a model should be rejected or revised in light of new data (Brown, 2015). The CFA was then carried out on the 11-item HTQ (see Supplementary Materials, Figure S2, Table S3), which indicated that the three-factor structure was adequate $\left(\chi^{2}(41,259)=104.901, p<0.001\right.$, RMSEA $=0.078[0.059,0.096]$, SRMR $=$ 0.055, $\mathrm{CFI}=0.934 ; \mathrm{TLI}=0.912$ ).

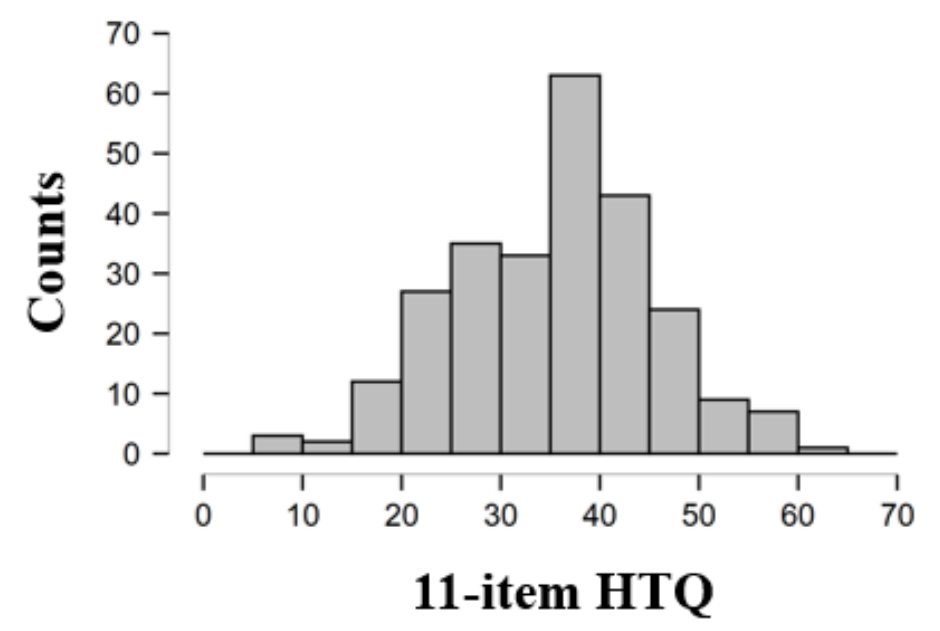

Figure 5. Distribution plot for 11-item Habitual Tendencies Questionnaire (HTQ). 


\section{Construct validity}

As evident in Table 3, all three HTQ subscales showed significant and strong positive correlations with the 11-item HTQ (with $\mathrm{r}$ values above 0.5 ), but only moderate correlations with each other (with $r$ values less than 0.5 ). This corroborates the factor analysis in suggesting that each subscale is representative of a distinct aspect of the habitual tendencies construct.

In order to evaluate the relationships between the HTQ and subclinical OCD symptomatology, we computed the Pearson's correlations for these variables (see Table 3). As evident in Table 3, there was a significant positive correlation between the HTQ and OCI scales $(r=0.258, p<0.001)$. Within the three subscales of the HTQ, the Compulsivity subscale contributed the most to this association (see Table 3 and Figure 6), as it showed the strongest correlation with the OCI $(r=0.461, p<0.001)$, whereas the Preference for Regularity and Aversion to Novelty subscales were not significantly correlated with the OCI. The Pearson's $r$ effect sizes of 0.258 and 0.461 are typical and relatively large, respectively, as per the individual differences research guidelines set out by Gignac and Szodorai (2016).

To complement the Pearson's correlations, we also examined the Bayes Factors (see Table 3), which demonstrated that that the relationship between HTQ Compulsivity and the OCI possesses an extremely large Bayes Factor of $5.094 \times 10^{11}$ (see Table 3), indicating that the observed data is $5.094 \times 10^{11}$ times more likely under $\mathrm{H}_{1}$ (significant correlation) than $\mathrm{H}_{0}$ (no correlation). As this Bayes Factor value is above 100, it indicates "extreme evidence" for $\mathrm{H}_{1}$, in line with the guidelines from Wagenmakers and colleagues (2018).

We then explored the relationships between the HTQ and the Creature of Habit Scale (COHS), a recently-developed self-report measure of habits. Descriptive statistics revealed that the COHS followed an approximately normal distribution, according to the Shapiro-Wilk test ( $p=0.146)$, with minimal skewness $(-0.266)$ and kurtosis $(-0.243)$. The mean total score on the COHS was $87.599(\mathrm{SD}=18.049)$, and it had a good Cronbach's $\alpha$ of $0.902,95 \% \mathrm{CI}=$ 
$[0.884,0.918]$. Cronbach's $\alpha$ values for each of the subscales were 0.887 for Routine, and 0.863 for Automaticity. CFA was carried out on the COHS, which indicated that the two-factor structure was borderline acceptable $\left(\chi^{2}(323)=743.635, p<0.001\right.$, RMSEA $=0.073[0.066$, 0.080], $\mathrm{SRMR}=0.069, \mathrm{CFI}=0.824 ; \mathrm{TLI}=0.809)$. As evident in Table 3, there were significant positive correlations between the HTQ and the COHS $(r=0.347, p<0.001)$, as well as their individual subscales. The largest of these correlations was between HTQ Regularity and COHS Routine $(r=0.309, p<0.001)$, suggesting that they may represent similar constructs.

Table 3. Correlation matrix of the Habitual Tendencies Questionnaire, Creature of Habit Scale and OCD traits, including Pearson's correlations and Bayes Factors.

\begin{tabular}{|c|c|c|c|c|c|c|c|c|}
\hline & & HTQ & $\begin{array}{c}\text { HTQ } \\
\text { Compulsivi } \\
\text { ty }\end{array}$ & $\begin{array}{c}\text { HTQ } \\
\text { Regularity }\end{array}$ & $\begin{array}{c}\text { HTQ } \\
\text { Aversion to } \\
\text { Novelty }\end{array}$ & OCI & $\begin{array}{c}\text { COHS } \\
\text { Total }\end{array}$ & $\begin{array}{l}\text { COHS } \\
\text { Routine }\end{array}$ \\
\hline \multirow{2}{*}{ HTQ } & $\mathrm{r}$ & - & & & & & & \\
\hline & $\mathrm{BF}_{10}$ & - & & & & & & \\
\hline \multirow{2}{*}{$\begin{array}{l}\text { HTQ } \\
\text { Compulsivity }\end{array}$} & $\mathrm{r}$ & $0.747 * * *$ & - & & & & & \\
\hline & $\mathrm{BF}_{10}$ & $1.188 \times 10^{44}$ & - & & & & & \\
\hline \multirow{2}{*}{$\begin{array}{l}\text { HTQ } \\
\text { Regularity }\end{array}$} & $\mathrm{r}$ & $0.782 * * *$ & $0.314 * * *$ & - & & & & \\
\hline & $\mathrm{BF}_{10}$ & $2.284 \times 10^{51}$ & 44224.531 & - & & & & \\
\hline \multirow{2}{*}{$\begin{array}{l}\text { HTQ Aversion } \\
\text { to Novelty }\end{array}$} & $r$ & $0.685 * * *$ & $0.198 * *$ & $0.465 * * *$ & - & & & \\
\hline & $\mathrm{BF}_{10}$ & $8.676 \times 10^{33}$ & 12.917 & $2.355 \times 10^{12}$ & - & & & \\
\hline \multirow[t]{2}{*}{ OCI } & $\mathrm{r}$ & $0.258 * * *$ & $0.461 * * *$ & 0.095 & -0.080 & - & & \\
\hline & $\mathrm{BF}_{10}$ & 404.171 & $5.094 \times 10^{11}$ & 0.240 & 0.173 & - & & \\
\hline \multirow{2}{*}{$\begin{array}{l}\text { COHS } \\
\text { Total }\end{array}$} & $\mathrm{r}$ & $0.347 * * *$ & $0.276 * * *$ & $\mathbf{0 . 3 0 2} * * *$ & $0.175 * *$ & $0.220 * * *$ & - & \\
\hline & $\mathrm{BF}_{10}$ & 348786.925 & 987.477 & 7300.442 & 3.245 & 24.957 & - & \\
\hline \multirow{2}{*}{$\begin{array}{l}\text { COHS } \\
\text { Routine }\end{array}$} & $\mathrm{r}$ & $0.312 * * *$ & $0.218 * * *$ & $0.309 * * *$ & $0.154 *$ & $0.190 * *$ & $0.881 * * *$ & - \\
\hline & $\mathrm{BF}_{10}$ & 15295.251 & 27.060 & 12651.433 & 1.391 & 5.728 & $1.882 \times 10^{76}$ & - \\
\hline \multirow{2}{*}{$\begin{array}{l}\text { COHS } \\
\text { Automaticity }\end{array}$} & $\mathrm{r}$ & $0.273 * * *$ & $0.253 * * *$ & $0.190 * *$ & 0.141* & $0.181 * *$ & 0.806*** & $\mathbf{0 . 4 3 0} * * *$ \\
\hline & $\mathrm{BF}_{10}$ & 788.434 & 211.415 & 6.454 & 0.887 & 3.746 & $1.326 \times 10^{53}$ & $3.020 \times 10^{9}$ \\
\hline
\end{tabular}

$* p<0.05, * * p<0.01, * * * p<0.001 ; \mathrm{BF}<3=$ Anecdotal evidence; $\mathrm{BF}<10=$ Moderate evidence; $\mathrm{BF}<30=$ Strong evidence; $\mathrm{BF}<100=$ Very strong evidence; $\mathrm{BF}>100=$ Extremely strong evidence.

HTQ = Habitual Tendencies Questionnaire. COHS = Creature of Habit Scale. OCI = Obsessive-Compulsive Inventory . 


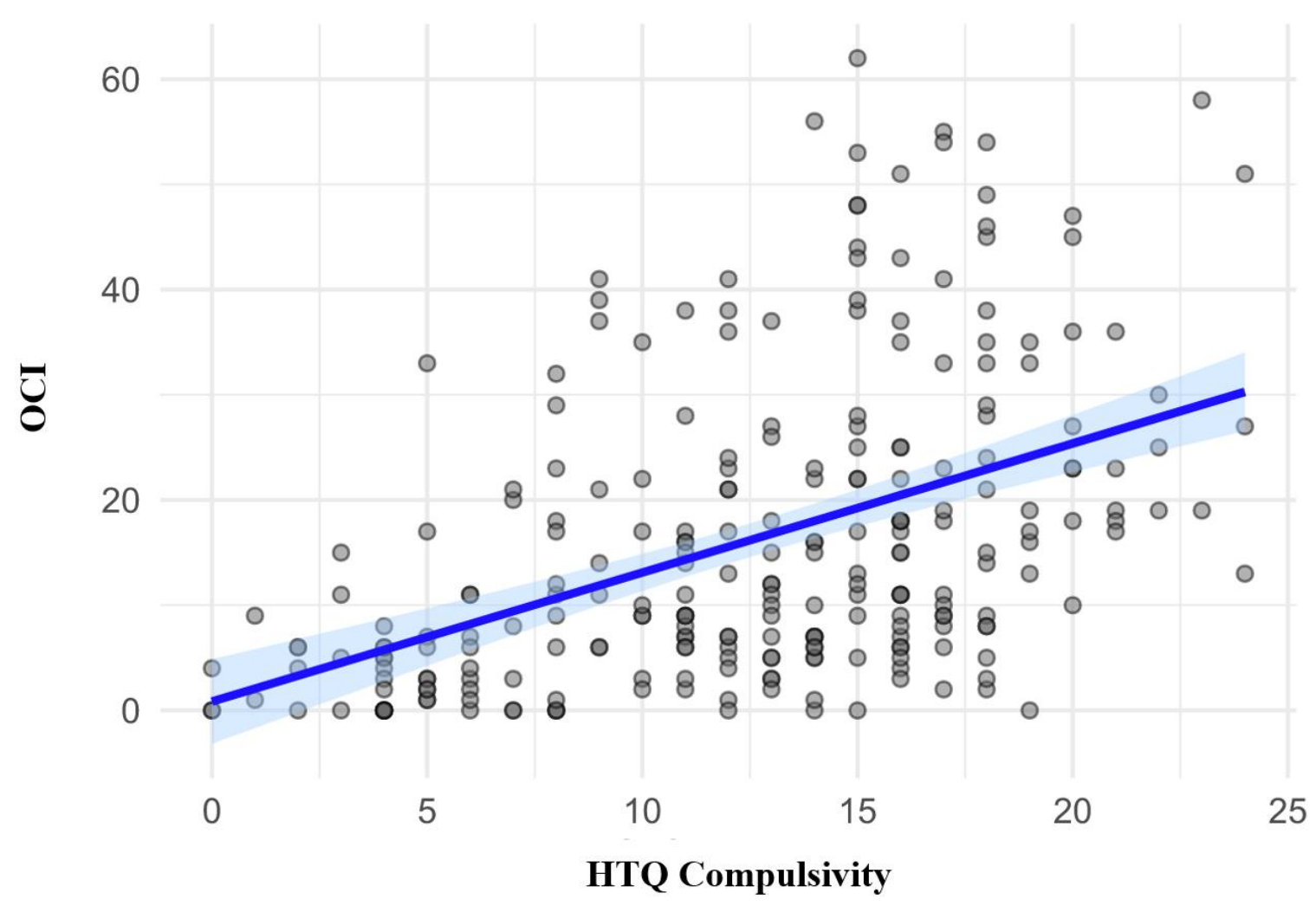

Figure 6. Scatter plot showing correlations between the Obsessive-Compulsive Inventory (OCI) and the Compulsivity subscale of the Habitual Tendencies Questionnaire (HTQ).

We then conducted a two-step hierarchical linear regression with the three subscales of the HTQ as predictors of subclinical OCD symptomatology, and age and gender as covariates. Of the demographic variables, only age was a significant predictor of subclinical OCD symptomatology $(\beta=-0.283, t(249)=-4.602, p<0.001)$, and of the three HTQ subscales, HTQ Compulsivity emerged as the most significant predictor of subclinical OCD symptomatology $(\beta=0.443, t(249)=7.262, p<0.001)$. The demographic variables alone explained $7.9 \%$ of the variance in subclinical OCD symptomatology $\left(R^{2}=0.079, F(2,247)=10.601, p<0.001\right)$, but addition of the three subscales of the HTQ in step 2 increased the $R^{2}$ term to 0.259 , accounting for a further $18 \%$ of the variance in subclinical OCD symptomatology $\left(R^{2}=0.259 F(3,244)=\right.$ $17.029, p<0.001)$.

\section{Interim Discussion}


Study 2 has replicated the findings of Study 1 and validated the 11-item HTQ in a larger sample. Confirmatory factor analysis (CFA) demonstrated that the three-factor structure of the HTQ was adequate, thus validating the 11 items subdivided into the three subscales for the final version of the HTQ. The Bayes factors and Pearson's correlations for the relationships between the HTQ, its subscales, subclinical OCD symptomatology, and the COHS, an existing measure of habitual tendencies, were then examined in order to determine the construct validity of the HTQ. There was a significant positive correlation between HTQ Compulsivity and the OCI, as in Study 1, suggesting that individuals prone to compulsivity show increased subclinical OCD symptomatology. Similarly, a significant positive correlation was found between HTQ Regularity and the Routine subscale of the COHS, suggesting that they tap into similar constructs. Hierarchical regression demonstrated that the three subscales of the HTQ explain a significant proportion of the variance in subclinical OCD symptomatology, and furthermore, revealed HTQ Compulsivity to be a significant predictor of subclinical OCD symptomatology, replicating the findings of Study 1 . Therefore, the HTQ may be used as a validated tool to measure individual variation in habitual tendencies, and its subscales may be valuable in predicting subclinical traits in the general population.

\section{Combined Analysis: Study $1+2$}

Finally, we analysed the combined data from Study 1 and 2 in order to determine whether the findings from Study 1 and Study 2 individually were still captured by this larger sample. The aims of this combined analysis were to replicate the relationship between HTQ Compulsivity and subclinical OCD symptomatology demonstrated in both Study 1 and Study 2, and to validate the 11-item HTQ in an even larger, better-powered sample. 


\section{Methods}

\section{Participants}

We combined the data from Study 1 and Study 2, which resulted in a total of 389 participants for analysis. The combined sample consisted of 54\% males, $45 \%$ females and $1 \%$ other/unspecified, between the ages of 19 and $73(\mathrm{M}=38.090, \mathrm{SD}=11.596)$. All participants were based in the United States of America. The sample identified as 69.7\% White, $11.8 \%$ Black or African American, 7.5\% Mixed ethnicity, 5.1\% Asian, 3.3\% Hispanic/Latino, 1.3\% American Indian or Alaska Native, $0.3 \%$ Native American/Pacific Islander, $0.8 \%$ other, $0.3 \%$ unspecified. The highest levels of educational attainment of the sample population were as follows: $0.5 \%$ had achieved less than a high school degree, $13.1 \%$ had graduated high school, $21.1 \%$ had completed some school but did not have a degree, $14.1 \%$ had completed a 2 -year Associate degree in college, $41.6 \%$ had completed a 4-year Bachelor's degree in college, $8.2 \%$ had a Master's degree, and 1.3\% had a Doctoral or Professional degree.

\section{Measures}

We administered the 37-item and 11-item versions of the HTQ in study 1 and study 2 respectively, rated on 7-point Likert scales ranging from "Strongly disagree" to "Strongly agree", along with the revised OCI (Foa et al., 2002), which had a high Cronbach's $\alpha$ value of 0.947. The surveys also included two interspersed attention checks, as in Study 1 and 2.

\section{Results}

After removing participants as detailed in Study 1 and Study 2 above, we conducted descriptive statistics and reliability analyses on the remainder of the data. 161 participants' results were removed, resulting in a final sample size of 389 for analysis. As shown in Figure 7, the HTQ scores followed an approximately normal distribution according to the ShapiroWilk test $(p=0.470)$, with minimal skewness $(-0.076)$ and kurtosis $(-0.008)$. The mean total 
score on the HTQ was found to be 35.465 (maximum possible score $=66$ ), with standard deviation 9.757, and a good Cronbach's $\alpha$ of 0.796 was calculated, with 95\% confidence interval $[0.764,0.825]$. Cronbach's $\alpha$ values for each of the subscales were 0.839 for Compulsivity, 0.775 for Preference for Regularity, and 0.706 for Aversion to Novelty. A CFA was carried out, which indicated that the three-factor structure was adequate $\left(\chi^{2}(41,389)=\right.$ 111.887, $p<0.001$, RMSEA $=0.067[0.052,0.082]$, SRMR $=0.047$, CFI $=0.952 ;$ TLI $=$ 0.936), see Supplementary Materials, Table S4.

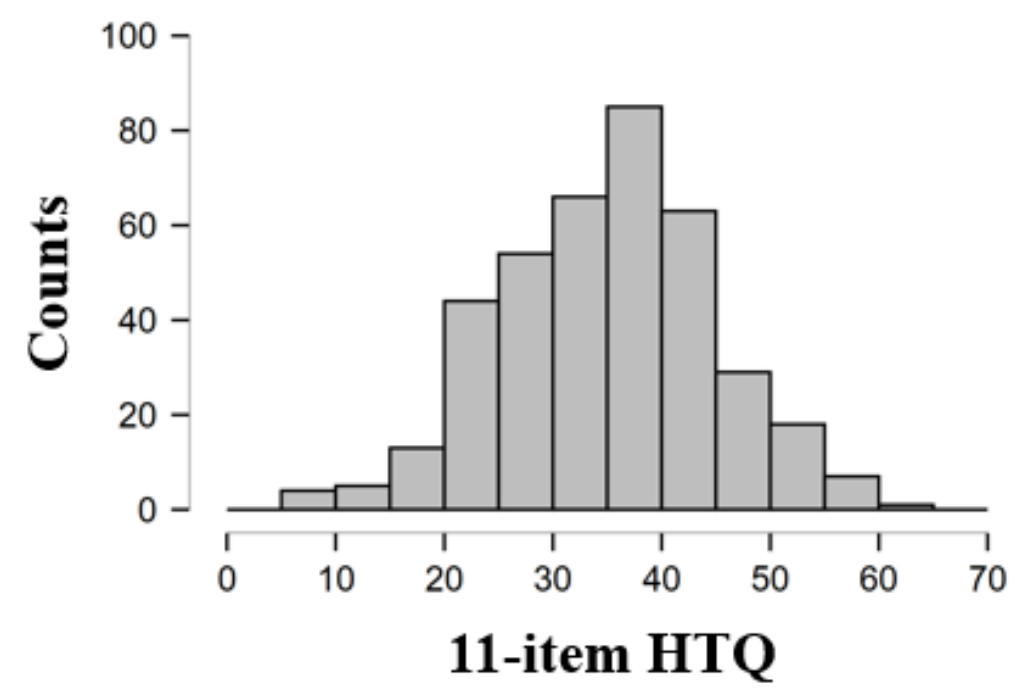

Figure 7. Distribution plot for 11-item Habitual Tendencies Questionnaire (HTQ).

\section{Construct validity}

As evident in Table 4, all three HTQ subscales showed significant and strong positive correlations with the 11-item HTQ (with $\mathrm{r}$ values above 0.5 ), but only weak correlations with each other (with $r$ values less than 0.5 ). This corroborates the factor analysis in suggesting that each subscale is representative of a distinct aspect of the habitual tendencies construct.

In order to evaluate the relationships between the HTQ and subclinical OCD symptomatology, we computed the Pearson's correlations for these variables (see Table 4). As evident in Table 4, there was a significant positive correlation between the HTQ and OCI scales 
$(r=0.330, p<0.001)$. Within the three subscales of the HTQ, the Compulsivity subscale contributed the most to this association (see Table 4 and Figure 8), as it showed the strongest correlation with the OCI $(r=0.508, p<0.001)$, whereas the Preference for Regularity subscale was much less significantly correlated with the OCI, and the Aversion to Novelty subscale was not significantly correlated with the OCI. The Pearson's $r$ effect sizes of 0.330 and 0.508 are relatively large, as per the individual differences research guidelines set out by Gignac and Szodorai (2016). To complement the Pearson's correlations, we also examined the Bayes Factors (see Table 4), which demonstrated that the relationship between HTQ Compulsivity and the OCI possesses an extremely large Bayes Factor of $1.639 \times 10^{23}$ (see Table 4), indicating that the observed data is $1.639 \times 10^{23}$ times more likely under $\mathrm{H}_{1}$ (significant correlation) than $\mathrm{H}_{0}$ (no correlation). As this Bayes Factor value is above 100, it indicates "extreme evidence" for $\mathrm{H}_{1}$, in line with the guidelines from Wagenmakers and colleagues (2018).

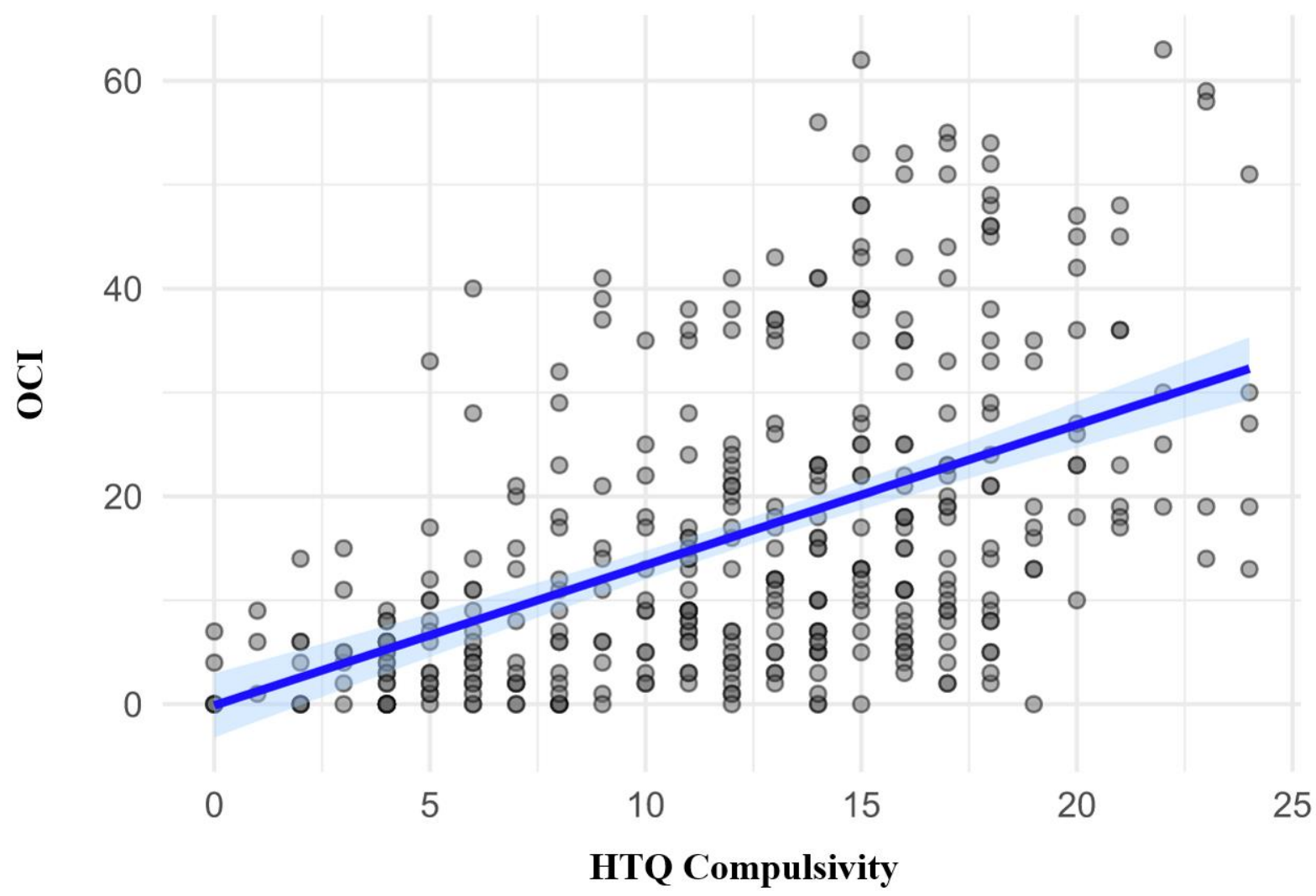

Figure 8. Scatter plot showing correlations between the Obsessive-Compulsive Inventory (OCI) and the Compulsivity subscale of the Habitual Tendencies Questionnaire (HTQ). 
Table 4. Correlation matrix of the Habitual Tendencies Questionnaire and OCD traits, including Pearson's correlations and Bayes Factors.

\begin{tabular}{|c|c|c|c|c|c|c|}
\hline & & HTQ & $\begin{array}{c}\text { HTQ } \\
\text { Compulsivit } \\
y\end{array}$ & $\begin{array}{c}\text { HTQ } \\
\text { Regularity }\end{array}$ & $\begin{array}{c}\text { HTQ } \\
\text { Aversion to } \\
\text { Novelty }\end{array}$ & OCI \\
\hline \multirow{2}{*}{$\begin{array}{l}\text { HTQ } \\
\text { Compulsivit } \\
\text { y }\end{array}$} & Pearson's r & $0.740 * * *$ & - & & & \\
\hline & $\mathrm{BF}_{10}$ & $1.292 \times 10^{65}$ & - & & & \\
\hline \multirow{2}{*}{$\begin{array}{l}\text { HTQ } \\
\text { Regularity }\end{array}$} & Pearson's r & $0.748 * * *$ & $0.262 * * *$ & - & & \\
\hline & $\mathrm{BF}_{10}$ & $2.809 \times 10^{67}$ & 58515.711 & - & & \\
\hline \multirow{2}{*}{$\begin{array}{l}\text { HTQ } \\
\text { Aversion to } \\
\text { Novelty }\end{array}$} & Pearson's r & $0.651 * * *$ & $0.154 * *$ & $0.406 * * *$ & - & \\
\hline & $\mathrm{BF}_{10}$ & $8.484 \times 10^{44}$ & 6.505 & $7.391 \times 10^{13}$ & - & \\
\hline \multirow[t]{2}{*}{ OCI } & Pearson's r & 0.330*** & $0.508 * * *$ & 0.112* & -0.017 & - \\
\hline & $\mathrm{BF}_{10}$ & $1.810 \times 10^{8}$ & $1.639 \times 10^{23}$ & 0.682 & 0.068 & - \\
\hline
\end{tabular}

$* p<0.05, * * p<0.01, * * * p<0.001 ; \mathrm{BF}<3=$ Anecdotal evidence; $\mathrm{BF}<10=$ Moderate evidence; $\mathrm{BF}<30=$ Strong evidence; $\mathrm{BF}<100=$ Very strong evidence; $\mathrm{BF}>100=$ Extremely strong evidence. HTQ = Habitual Tendencies Questionnaire. OCI = Obsessive-Compulsive Inventory.

We then conducted a two-step hierarchical linear regression with the three subscales of the HTQ as predictors of subclinical OCD symptomatology, and age and gender as covariates. Of the demographic variables, only age was a significant predictor of subclinical OCD symptomatology $(\beta=-0.263, t(376)=-5.181, p<0.001)$, and of the three HTQ subscales, HTQ Compulsivity emerged as the most significant predictor of subclinical OCD symptomatology $(\beta=0.477, t(376)=10.174, p<0.001)$. The demographic variables alone explained $6.7 \%$ of the variance in subclinical OCD symptomatology $\left(R^{2}=0.067, F(2,374)=13.502, p<0.001\right)$, but addition of the three subscales of the HTQ in step 2 increased the $R^{2}$ term to 0.283 , accounting for a further $21.6 \%$ of the variance in subclinical OCD symptomatology $\left(R^{2}=0.283\right.$ $F(3,371)=29.308, p<0.001)$. 


\section{Discussion}

The present study has developed and validated a key research tool for measuring individual differences in habitual tendencies, the Habitual Tendencies Questionnaire (HTQ). Through a rigorous process of selection, 11 items were chosen for the final version of the HTQ, and factor analysis revealed that these items clustered into three factors, representing three distinct aspects of the habitual tendencies construct: Compulsivity, Preference for Regularity, and Aversion to Novelty. The three-factor structure of the HTQ was reliably maintained across two independent samples, including a preregistered replication, and a combined summative analysis, and was shown to be able to discriminate between various features of habitual tendencies (encompassing behaviours, attitudes, beliefs and thinking styles) in healthy populations. Participants' scores on the Compulsivity subscale of the HTQ consistently showed a significant strong positive correlation with their subclinical OCD symptoms, suggesting that individuals prone to compulsive thoughts and actions in their normative daily lives show increased subclinical OCD symptomatology.

The present study highlights the importance of recognising that habits are composed of different facets that manifest in the daily lives of individuals to varying degrees, and of making distinctions between these facets. This is consistent with recent research such as that of Hardwick and colleagues (2019), who found a difference between the formation of habits and their expression. They propose that a stimulus triggers the preparation of a response, but that this response is not enacted immediately. Therefore, a more appropriate, goal-directed action may replace the prepared response before it can be initiated. In Hardwick and colleagues' (2019) study, participants practised a visuomotor association task for 4 days. They then learned a new association, but when forced to respond rapidly, habitually expressed the old association. This demonstrates a dissociation between habit formation and expression, which may be reflective of the different aspects of habitual tendencies encompassed by the HTQ, such as 
thinking style (HTQ Compulsivity) or attitude (HTQ Preference for Regularity), and behaviour (HTQ Aversion to Novelty).

Elucidating the underlying components of habits has important implications for our understanding of the antecedents of clinical disorders involving excessive habits, such as OCD. Dissociations similar to those of Hardwick and colleagues (2019) have been made in relation to different aspects of OCD, which may arise, in part, as a result of an over-reliance on habits, as well as deficits in goal-directed control (e.g. Gillan et al., 2016). The ego-dystonic nature of OCD means that patients possess the knowledge that their behaviour is irrational, and this has been demonstrated experimentally using a contingency degradation task (Vaghi et al., 2018). Although patients with OCD showed exaggerated responding compared with healthy controls, their action-outcome contingency knowledge was intact, implying a divergence between their actions or behaviours; and their knowledge, or thinking style. Furthermore, it has been suggested that the obsessions (represented by habit learning) and compulsions (represented by habit perseverance) underlying OCD may themselves be attributable to distinct systems and even neural circuitries (Robbins et al., 2019). Revisiting a PET study conducted by Rauch and colleagues (1998), which explored the neural correlates of factor-analysed OCD symptoms, provides support for this. Religious, aggressive and sexual obsessions, and checking compulsions (Factor 1 in Rauch et al., 1998) were positively associated with bilateral striatal activity, while symmetry and ordering symptoms (Factor 2 in Rauch et al., 1998) were negatively associated with right caudate nucleus activity. Washing and cleaning symptoms (Factor 3 in Rauch et al., 1998) were positively associated with activity in several prefrontal areas. The grouping of OCD symptoms into the different factors reflects the dissociation between obsessions (as Factor 1 consisted of symptoms relating to thinking style), and compulsions (as Factors 2 and 3 consisted of symptoms relating to behaviours), and the distinct 
neural correlates of these different dimensions reinforce the notion that $\mathrm{OCD}$, and the habitual tendencies underlying it, are composed of various dimensions.

An important future direction may be to explore whether the different components of the HTQ map onto distinct neural circuitries in a similar way, as subclinical OCD symptomatology is associated with HTQ Compulsivity, but not with the other HTQ subscales. Extensive evidence from neuroscientific studies of experimental animals and neuroimaging studies in humans has supported the concept of dual systems of behavioural control; a goaldirected system, implicating the ventromedial prefrontal cortex (vmPFC) and caudate nucleus, and a habit system which recruits the putamen and premotor regions of cortex (Balleine and O'Doherty 2010). Compulsivity as measured by questionnaire scales in a large sample of adolescents has been linked to reduced white matter in dorsomedial and dorsolateral PFC regions, especially including the anterior cingulate cortex and the ventral striatum. Moreover. compulsive behaviour in addiction and OCD, as measured respectively by the ObsessiveCompulsive Drug Use Scale (OCDUS) and the Yale-Brown Obsessive-Compulsive Scale (YBOCS) has been linked to structural changes or dysconnectivity of the ventromedial and orbitofrontal PFC (Meunier et al 2012; Ersche et al 2011). One interpretation of these findings is that underactivity in these PFC circuits leads either to an imbalance in the goal-directed versus habit systems, or a dysregulated control over the striatal habit system (e.g. Hardwick et al 2019), thus linking compulsivity to enhanced habits. Future studies should aim to link these neural studies with experimental measures of habit learning and compulsivity scales, such as OCD with habit scales such as HTQ or COHS, to validate the laboratory test paradigms against habitual behaviour in the real world. For example. Ersche and colleagues (2021) showed that a shift to habitual control, as assessed with contingency degradation procedure, was impaired in chronic cocaine abusers, and additionally that contingency degradation performance was 
positively related to the automaticity score on the COHS, which in turn in this group, was significantly related to reductions in glutamate turnover in the putamen.

Additionally, the present study demonstrated robust individual differences in habitual tendencies, which may help to explain past inconsistencies between animal and human research, and between empirical and theoretical work. De Wit and colleagues (2018) attempted to induce habits in human participants using five outcome devaluation tasks, but this was unsuccessful, leading them to conclude that these tasks are mainly a measure of goal-directed control, and thus compulsive individuals perform less well in these tasks due to impaired goaldirected control rather than overactive habit learning. However, individual differences in habitual tendencies were unaccounted for in most of these experiments or deliberately cancelled out. We propose that individual differences in susceptibilities to habitual tendencies may have a significant impact on the findings, or lack thereof, in studies such as this one. A study conducted by Luijten and colleagues (2020) provides support for this view. This study found that although there was no difference in habitual versus goal-directed control between smokers and non-smoking controls in outcome devaluation tasks, individual differences in nicotine dependence within the smoking group were positively correlated with habitual responding after appetitive instrumental learning, modelling positive reinforcement. This emphasises the importance of individual differences in this field of research, and suggests that individual variation in susceptibilities to habits must be taken into account in order to effectively manipulate habitual tendencies.

The results obtained in the present study possess important implications for future research and intervention. As the present study used an online convenience sample, replication of these findings in countries other than the USA would be useful in order to explore whether the present findings are consistent across cultural contexts. In addition, the 11-item HTQ may be used in individual difference research on habitual tendencies and their associations with 
other constructs, such as personality traits and political views (e.g. Zmigrod et al., 2018). It may also be fruitful to extend the present findings by using existing behavioural measures of habits, such as the Fabulous Fruit Game (de Wit et al., 2007) and outcome devaluation paradigms (e.g. Gillan et al., 2011), as well as measures of goal-directed control, such as contingency degradation paradigms (e.g. Vaghi et al., 2019), in conjunction with the HTQ in order to strengthen the reliability and validity of the present findings, and to contribute to theories that try to understand the causal mechanisms that make some individuals more susceptible to habitual tendencies, and more specifically, to compulsive thinking. It has been suggested that many of the supposed behavioural measures of habits in fact measure impaired goal-directed control (de Wit et al., 2018), and as such, there may be a need for the development of novel behavioural paradigms that measure habits more specifically. In addition, there may be a role for the administration of other cognitive tasks, such as the Alternative Uses Task (Guildford, 1967; Ionescu, 2012; Zmigrod et al., 2019), along with the HTQ, to improve our understanding of how individual variation in cognitive inflexibility may moderate habitual tendencies, and contribute to disorders involving these traits (Ramakrishnan, Robbins \& Zmigrod, in prep).

Another important future direction would be to explore relationships between the HTQ and various clinical disorders associated with habits. This could be achieved by administering the HTQ to those with clinically diagnosed OCD, as well as to alternative populations of individuals with disorders involving compulsivity, such as addictions and binge eating disorders, which have been suggested to involve "deficits in goal-directed control and associated over-reliance on habits" (Gillan et al., 2016, p.836). Another disorder that may be of interest to study in relation to habitual tendencies is autism and autism spectrum disorders, as the present study found a significant positive correlation between the HTQ and the Autism Quotient (Allison et al., 2012), (see Supplementary Materials, Additional Analyses and Table 
S5) and there is often comorbidity between OCD and autism, as well as overlap in their symptomatology (Leyfer et al., 2006). Thus, future investigations may identify convergences and divergences in patterns of habitual tendencies across different clinical disorders.

To conclude, the present study developed and validated a novel, representative measure of habitual tendencies, the Habitual Tendencies Questionnaire (HTQ), which has good reliability and validity. The HTQ may prove useful in future research into habitual tendencies, including in relation to compulsivity disorders such as OCD, potentially contributing to the development of interventions targeting the maladaptive habits proposed to underlie OCD. To return to William James's Habit (1890, p.3-4), it “thus appears that habit covers a very large part of life, and that one engaged in studying the objective manifestations of mind is bound at the very outset to define clearly just what its limits are".

\section{Acknowledgements}

We would like to acknowledge Bushra Zafar, Paul Matthews, and Chessie Broadhurst for research assistance and help in developing the Habitual Tendencies Questionnaire. This research was made possible through a Gates Cambridge Scholarship and a Junior Research Fellowship by Churchill College, Cambridge, to Leor Zmigrod, and a Wellcome Trust Senior Investigator Grant to Trevor Robbins. 


\section{References}

Allison, C., Auyeung, B., \& Baron-Cohen, S. (2012). Toward brief "red flags" for autism screening: the short autism spectrum quotient and the short quantitative checklist in 1,000 cases and 3,000 controls. Journal of the American Academy of Child \& Adolescent Psychiatry, 51(2), 202-212.

Armitage, C. J., \& Christian, J. (2003). From attitudes to behaviour: Basic and applied research on the theory of planned behaviour. Current Psychology, 22(3), 187-195.

Balleine, B.W., and O'Doherty, J.P. (2010). Human and rodent homologies in action control: corticostriatal determinants of goal-directed and habitual action. Neuropsychopharmacology $35,48-69$.

Bari, A., \& Robbins, T. W. (2013). Inhibition and impulsivity: behavioral and neural basis of response control. Progress in neurobiology, 108, 44-79.

Bar-Tal, Y. (1994). The effect on mundane decision-making of the need and ability to achieve cognitive structure. European Journal of Personality, 8(1), 45-58.

Berg, E. A. (1948). A simple objective technique for measuring flexibility in thinking. The Journal of general psychology, 39(1), 15-22.

Brown, T. A. (2015). Confirmatory factor analysis for applied research. Guilford publications.

Chamberlain, S. R., Fineberg, N. A., Blackwell, A. D., Robbins, T. W., \& Sahakian, B. J. (2006). Motor inhibition and cognitive flexibility in obsessive-compulsive disorder and trichotillomania. American Journal of Psychiatry, 163(7), 1282-1284.

Cheung, J. H., Burns, D. K., Sinclair, R. R., \& Sliter, M. (2017). Amazon Mechanical Turk in Organizational Psychology: An Evaluation and Practical Recommendations. Journal of Business and Psychology, 32(4), 347-361. https://doi.org/10.1007/s10869-016-9458-5

Dajani, D. R., \& Uddin, L. Q. (2015). Demystifying cognitive flexibility: implications for clinical and developmental neuroscience. Trends in neurosciences, 38(9), 571-578.

De Wit, S., Niry, D., Wariyar, R., Aitken, M. R. F., \& Dickinson, A. (2007). Stimulus-outcome interactions during instrumental discrimination learning by rats and humans. Journal of Experimental Psychology: Animal Behavior Processes, 33(1), 1.

De Wit, S., Kindt, M., Knot, S. L., Verhoeven, A. A., Robbins, T. W., Gasull-Camos, J., ... \& Gillan, C. M. (2018). Shifting the balance between goals and habits: Five failures in experimental habit induction. Journal of Experimental Psychology: General, 147(7), 1043.

Downes, J. J., Roberts, A. C., Sahakian, B. J., Evenden, J. L., Morris, R. G., \& Robbins, T. W. (1989). Impaired extra-dimensional shift performance in medicated and unmedicated Parkinson's disease: evidence for a specific attentional dysfunction. Neuropsychologia, 27(1112), 1329-1343. 
Ersche, K. D., Lim, T. V., Ward, L. H., Robbins, T. W., \& Stochl, J. (2017). Creature of Habit: A self-report measure of habitual routines and automatic tendencies in everyday life. Personality and individual differences, 116, 73-85.

Ersche, K. D., Ward, L. H., Lim, T. V., Lumsden, R. J., Sawiak, S. J., Robbins, T. W., \& Stochl, J. (2019). Impulsivity and compulsivity are differentially associated with automaticity and routine on the Creature of Habit Scale. Personality and individual differences, 150, 109493.

Ersche, K.D., Barnes, A., Jones, P.S., Morein-Zamir, S., Robbins, T.W. \& Bullmore, E.T. (2011) Abnormal structure of frontostriatal brain systems is associated with aspects of impulsivity and compulsivity in cocaine dependence. Brain, 134, 2013-2024. https://doi.org/10.1093/brain/awr138 PMID: 21690575.

Ersche KD, Lim TV, Murley A, Rua C, Vaghi M, White TL, Williams GB, Robbins TW (2021) Reduced Glutamate Turnover in the Putamen Is Linked With Automatic Habits in Human Cocaine Addiction. Biol Psychiat https://doi.org/10.1016/j.biopsych.2020.12.009

Everitt, B. J., \& Robbins, T. W. (2016). Drug addiction: updating actions to habits to compulsions ten years on. Annual review of psychology, 67, 23-50.

Foa, E. B., Huppert, J. D., Leiberg, S., Langner, R., Kichic, R., Hajcak, G., \& Salkovskis, P. M. (2002). The Obsessive-Compulsive Inventory: development and validation of a short version. Psychological assessment, 14(4), 485.

Frenkel-Brunswik, E. (1949). Intolerance of ambiguity as an emotional and perceptual personality variable. Journal of personality, 18(1), 108-143.

Gignac, G. E., \& Szodorai, E. T. (2016). Effect size guidelines for individual differences researchers. Personality and individual differences, 102, 74-78.

Gillan, C. M., Papmeyer, M., Morein-Zamir, S., Sahakian, B. J., Fineberg, N. A., Robbins, T. W., \& de Wit, S. (2011). Disruption in the balance between goal-directed behavior and habit learning in obsessive-compulsive disorder. American Journal of Psychiatry, 168(7), 718-726.

Gillan, C. M., Morein-Zamir, S., Urcelay, G. P., Sule, A., Voon, V., Apergis-Schoute, A. M., ... \& Robbins, T. W. (2014). Enhanced avoidance habits in obsessive-compulsive disorder. Biological psychiatry, 75(8), 631-638.

Gillan, C. M., \& Robbins, T. W. (2014). Goal-directed learning and obsessive-compulsive disorder. Philosophical Transactions of the Royal Society B: Biological Sciences, 369(1655), 20130475.

Gillan, C. M., Apergis-Schoute, A. M., Morein-Zamir, S., Urcelay, G. P., Sule, A., Fineberg, N. A., ... \& Robbins, T. W. (2015). Functional neuroimaging of avoidance habits in obsessivecompulsive disorder. American Journal of Psychiatry, 172(3), 284-293.

Gillan, C. M., \& Sahakian, B. J. (2015). Which is the driver, the obsessions or the compulsions, in OCD?. Neuropsychopharmacology, 40(1), 247. 
Gillan, C. M., Robbins, T. W., Sahakian, B. J., van den Heuvel, O. A., \& van Wingen, G. (2016). The role of habit in compulsivity. European Neuropsychopharmacology, 26(5), 828840.

Graybiel, A. M., \& Rauch, S. L. (2000). Toward a neurobiology of obsessive-compulsive disorder. Neuron, 28(2), 343-347.

Guilford, J. P. (1967). The nature of human intelligence.

Hardwick, R. M., Forrence, A. D., Krakauer, J. W., \& Haith, A. M. (2019). Time-dependent competition between goal-directed and habitual response preparation. Nature human behaviour, 3(12), 1252-1262.

IBM Corp. Released 2020. IBM SPSS Statistics for Windows, Version 27.0. Armonk, NY: IBM Corp

Ionescu, T. (2012). Exploring the nature of cognitive flexibility. New ideas in psychology, 30(2), 190-200.

James, W. (1890). Habit. H. Holt.

JASP Team (2020). JASP (Version 0.12) [Computer software].

Jeffreys, H. (1961). Theory of probability, Clarendon.

Kruglanski, A. W. (1990). Motivations for judging and knowing: Implications for causal attribution.

Krumrei-Mancuso, E. J., \& Rouse, S. V. (2016). The development and validation of the comprehensive intellectual humility scale. Journal of Personality Assessment, 98(2), 209-221.

Lally, P., \& Gardner, B. (2013). Promoting habit formation. Health Psychology Review, 7(sup1), S137-S158.

Leyfer, O. T., Folstein, S. E., Bacalman, S., Davis, N. O., Dinh, E., Morgan, J., ... \& Lainhart, J. E. (2006). Comorbid psychiatric disorders in children with autism: interview development and rates of disorders. Journal of autism and developmental disorders, 36(7), 849-861.

Luijten, M., Gillan, C. M., De Wit, S., Franken, I. H., Robbins, T. W., \& Ersche, K. D. (2020). Goal-directed and habitual control in smokers. Nicotine and Tobacco Research, 22(2), 188195.

Mac Donald Jr, A. P. (1970). Revised scale for ambiguity tolerance: Reliability and validity. Psychological reports, 26(3), 791-798.

Meade, A. W., \& Craig, S. B. (2012). Identifying careless responses in survey data. Psychological Methods, 17(3), 437. 
Meiran, N., Diamond, G. M., Toder, D., \& Nemets, B. (2011). Cognitive rigidity in unipolar depression and obsessive compulsive disorder: Examination of task switching, Stroop, working memory updating and post-conflict adaptation. Psychiatry research, 185(1-2), 149-156.

Meunier, D., Ersche, K.D., Craig, K.J., Fornito, A., Merlo-Pich, E.M., Fineberg, N.A., Shabbir, S.S, Robbins, T.W. \& Bullmore, E.T. (2012) Brain functional connectivity in stimulant drug dependence and obsessive-compulsive disorder. Neuroimage, 59, 1461-1468. https://doi.org/10.1016/j.neuroimage.2011.08.003 PMID: 21871569.

Ramakrishnan, Robbins \& Zmigrod (in prep). The Habitual Tendencies Questionnaire: A Tool for Psychometric Individual Differences Research.

Rauch, S. L., Dougherty, D. D., Shin, L. M., Alpert, N. M., Manzo, P., Leahy, L., ... \& Baer, L. (1998). Neural correlates of factor-analyzed OCD symptom dimensions: a PET study. CNS spectrums, 3(7), 37-43.

Robbins, T. W., Gillan, C. M., Smith, D. G., de Wit, S., \& Ersche, K. D. (2012). Neurocognitive endophenotypes of impulsivity and compulsivity: towards dimensional psychiatry. Trends in cognitive sciences, 16(1), 81-91.

Robbins, T. W., \& Costa, R. M. (2017). Habits. Current Biology, 27(22), R1200-R1206.

Robbins, T. W., Gillan, C. M., Smith, D. G., de Wit, S., \& Ersche, K. D. (2012). Neurocognitive endophenotypes of impulsivity and compulsivity: towards dimensional psychiatry. Trends in cognitive sciences, 16(1), 81-91.

Robbins, T. W., Vaghi, M. M., \& Banca, P. (2019). Obsessive-compulsive disorder: puzzles and prospects. Neuron, 102(1), 27-47.

RStudio Team (2020). RStudio: Integrated Development for R. RStudio, Inc., Boston, MA U RL http://www.rstudio.com/.

Sjoerds, Z., de Wit, S., van den Brink, W., Robbins, T. W., Beekman, A. T., Penninx, B. W., \& Veltman, D. J. (2013). Behavioral and neuroimaging evidence for overreliance on habit lea rning in alcohol-dependent patients. Translational psychiatry, 3(12), e337-e337.

Stanley Budner, N. Y. (1962). Intolerance of ambiguity as a personality variable 1. Journal of personality, 30(1), 29-50.

Sternheim, L., van der Burgh, M., Berkhout, L. J., Dekker, M. R., \& Ruiter, C. (2014). Poor cognitive flexibility, and the experience thereof, in a subclinical sample of female students with obsessive-compulsive symptoms. Scandinavian journal of psychology, 55(6), 573-577.

Thompson, B. (2007). Factor analysis. The Blackwell Encyclopedia of Sociology.

Tyagi, H., Apergis-Schoute, A. M., Akram, H., Foltynie, T., Limousin, P., Drummond, L. M., ... \& Sahakian, B. J. (2019). A Randomised Trial Directly Comparing Ventral Capsule and Anteromedial Subthalamic Nucleus Stimulation in Obsessive Compulsive Disorder: Clinical and Imaging Evidence for Dissociable Effects. Biological Psychiatry. 
Vaghi, M. M., Vértes, P. E., Kitzbichler, M. G., Apergis-Schoute, A. M., van der Flier, F. E., Fineberg, N. A., ... \& Bullmore, E. T. (2017). Specific frontostriatal circuits for impaired cognitive flexibility and goal-directed planning in obsessive-compulsive disorder: evidence from resting-state functional connectivity. Biological psychiatry, 81(8), 708-717.

van't Riet, J., Sijtsema, S. J., Dagevos, H., \& De Bruijn, G. J. (2011). The importance of habits in eating behaviour. An overview and recommendations for future research. Appetite, 57(3), 585-596.

Verplanken, B., \& Aarts, H. (1999). Habit, attitude, and planned behaviour: Is habit an empty construct or an interesting case of automaticity? European Review of Social Psychology, 10, 101-134.

Verplanken, B., \& Orbell, S. (2003). Reflections on Past Behavior: A Self-Report Index of Habit Strength 1. Journal of applied social psychology, 33(6), 1313-1330.

Wagenmakers, E. J., Love, J., Marsman, M., Jamil, T., Ly, A., Verhagen, J., ... \& Meerhoff, F. (2018). Bayesian inference for psychology. Part II: Example applications with JASP. Psychonomic bulletin \& review, 25(1), 58-76.

Webster, D. M., \& Kruglanski, A. W. (1994). Individual differences in need for cognitive closure. Journal of personality and social psychology, 67(6), 1049.

Wood, W., \& Neal, D. T. (2007). A new look at habits and the habit-goal interface. Psychological review, 114(4), 843.

Zmigrod, L., Rentfrow, P. J., \& Robbins, T. W. (2018). Cognitive underpinnings of nationalistic ideology in the context of Brexit. Proceedings of the National Academy of Sciences, 115(19), E4532-E4540.

Zmigrod, L., Zmigrod, S., Rentfrow, P. J., \& Robbins, T. W. (2019). The psychological roots of intellectual humility: The role of intelligence and cognitive flexibility. Personality and Individual Differences, 141, 200-208.

\section{References for 27 scales identified in literature/citation searches}

Bar-Tal, Y. (1994). The effect on mundane decision-making of the need and ability to achieve cognitive structure. European Journal of Personality, 8(1), 45-58.

Cacioppo, J. T., Petty, R. E., \& Feng Kao, C. (1984). The efficient assessment of need for cognition. Journal of personality assessment, 48(3), 306-307.

Carleton, R. N., Norton, M. P. J., \& Asmundson, G. J. (2007). Fearing the unknown: A short version of the Intolerance of Uncertainty Scale. Journal of anxiety disorders, 21(1), 105-117.

Ehring, T., Zetsche, U., Weidacker, K., Wahl, K., Schönfeld, S., \& Ehlers, A. (2011). The Perseverative Thinking Questionnaire (PTQ): Validation of a content-independent measure of 
repetitive negative thinking. Journal of behavior therapy and experimental psychiatry, 42(2), $225-232$.

Ersche, K. D., Lim, T. V., Ward, L. H., Robbins, T. W., \& Stochl, J. (2017). Creature of Habit: A self-report measure of habitual routines and automatic tendencies in everyday life. Personality and individual differences, 116, 73-85.

Evans, D. W., Leckman, J. F., Carter, A., Reznick, J. S., Henshaw, D., King, R. A., \& Pauls, D. (1997). Ritual, habit, and perfectionism: The prevalence and development of compulsivelike behavior in normal young children. Child development, 68(1), 58-68.

Foa, E. B., Huppert, J. D., Leiberg, S., Langner, R., Kichic, R., Hajcak, G., \& Salkovskis, P. M. (2002). The Obsessive-Compulsive Inventory: development and validation of a short version. Psychological assessment, 14(4), 485.

Freeston, M. H., Rhéaume, J., Letarte, H., Dugas, M. J., \& Ladouceur, R. (1994). Why do people worry?. Personality and individual differences, 17(6), 791-802.

Gardner, B., Abraham, C., Lally, P., \& de Bruijn, G. J. (2012). Towards parsimony in habit measurement: Testing the convergent and predictive validity of an automaticity subscale of the Self-Report Habit Index. International Journal of Behavioral Nutrition and Physical Activity, 9(1), 102.

Gerrity, M. S., DeVellis, R. F., \& Earp, J. A. (1990). Physicians' reactions to uncertainty in patient care: a new measure and new insights. Medical care, 724-736.

Greco, V., \& Roger, D. (2001). Coping with uncertainty: The construction and validation of a new measure. Personality and individual differences, 31(4), 519-534.

Guay, F., Vallerand, R. J., \& Blanchard, C. (2000). On the assessment of situational intrinsic and extrinsic motivation: The Situational Motivation Scale (SIMS). Motivation and emotion, $24(3), 175-213$.

Hancock, J., Roberts, M., Monrouxe, L., \& Mattick, K. (2015). Medical student and junior doctors' tolerance of ambiguity: development of a new scale. Advances in Health Sciences Education, 20(1), 113-130.

Herman, J. L., Stevens, M. J., Bird, A., Mendenhall, M., \& Oddou, G. (2010). The tolerance for ambiguity scale: Towards a more refined measure for international management research. International Journal of Intercultural Relations, 34(1), 58-65.

Hodgson, R. J., \& Rachman, S. (1977). Obsessional-compulsive complaints. Behaviour research and therapy, 15(5), 389-395.

Mac Donald Jr, A. P. (1970). Revised scale for ambiguity tolerance: Reliability and validity. Psychological reports, 26(3), 791-798.

Nolen-Hoeksema, S. (2000). The role of rumination in depressive disorders and mixed anxiety/depressive symptoms. Journal of abnormal psychology, 109(3), 504. 
Norton, R. W. (1975). Measurement of ambiguity tolerance. Journal of personality assessment, 39(6), 607-619.

Roets, A., \& Van Hiel, A. (2011). Item selection and validation of a brief, 15-item version of the Need for Closure Scale. Personality and Individual Differences, 50(1), 90-94.

Schroder, K. E. E., Ollis, C. L., \& Davies, S. (2013). Habitual self-control: A brief measure of persistent goal pursuit. European Journal of Personality, 27(1), 82-95.

Stanley Budner, N. Y. (1962). Intolerance of ambiguity as a personality variable 1. Journal of personality, 30(1), 29-50.

Thompson, M. M., Naccarato, M. E., Parker, K. C., \& Moskowitz, G. B. (2001). The personal need for structure and personal fear of invalidity measures: Historical perspectives, current applications, and future directions. In Cognitive social psychology: The Princeton symposium on the legacy and future of social cognition (pp. 19-39).

Vaghi, M. M., Cardinal, R. N., Apergis-Schoute, A. M., Fineberg, N. A., Sule, A., \& Robbins, T. W. (2019). Action-outcome knowledge dissociates from behavior in obsessive-compulsive disorder following contingency degradation. Biological Psychiatry: Cognitive Neuroscience and Neuroimaging, 4(2), 200-209.

Verplanken, B., \& Orbell, S. (2003). Reflections on Past Behavior: A Self-Report Index of Habit Strength 1. Journal of applied social psychology, 33(6), 1313-1330.

Webster, D. M., \& Kruglanski, A. W. (1994). Individual differences in need for cognitive closure. Journal of personality and social psychology, 67(6), 1049.

Zmigrod, L., Rentfrow, P. J., \& Robbins, T. W. (2018). Cognitive underpinnings of nationalistic ideology in the context of Brexit. Proceedings of the National Academy of Sciences, 115(19), E4532-E4540. 


\section{Appendix}

\section{1-Item Habitual Tendencies Questionnaire}

HTQ Compulsivity

HTQ 37: I tend to dwell on the same issues

HTQ 36: I mentally fixate on certain issues and can't move on

HTQ 35: The same thoughts often keep going through my mind over and over again

HTQ 33: I tend to repeat actions because I keep doubting that I have done them properly

HTQ Preference for Regularity

HTQ 10: I like to have a regular, unchanging schedule

HTQ 9: There is comfort in regularity

HTQ 27: A good job has clear guidelines on what to do and how to do it

HTQ 1: I hate it when my routines are disrupted

HTQ Aversion to Novelty

HTQ 30: I look forward to new experiences $R$

HTQ 26: Life is boring if you never take risks and always play it safe $\mathrm{R}$

HTQ 7: When eating at restaurants, I like to try new dishes rather than ones I have tried before $\mathrm{R}$ 


\section{Supplementary Materials}

\section{Extended 37-Item Habitual Tendencies Questionnaire}

Items in original 37-item HTQ, categorised according to our 4 proposed aspects of habits (behaviour, attitude, belief and thinking style)

1) Behaviour - individual differences in dependence on routines or habits in daily life

HTQ 1: I hate it when my routines are disrupted

HTQ 2: I tend to change my plans last minute $R$

HTQ 3: I avoid situations where unexpected things might happen

HTQ 17: I always go on vacation to the same destination

HTQ 5: I like being spontaneous $R$

HTQ 6: I tend to stick with technology that I am familiar with for as long as I can

HTQ 18: I tend to do things in the same order every morning

HTQ 7: When eating at restaurants, I like to try new dishes rather than ones I have tried before $\mathrm{R}$

HTQ 8: It greatly bothers me when someone picks up one of my belongings and does not put it back exactly in its original place

2) Attitude - desire for structure or order in life (which might make individuals routine-prone) HTQ 10: I like to have a regular, unchanging schedule HTQ 11: Vacations often cause me stress

HTQ 12: I'd rather understand why things turned out a certain way than just let them happen HTQ 14: I like tasks that require very little thought once I've learned them

HTQ 4: I feel anxious when things change frequently

HTQ 30: I look forward to new experiences R

HTQ 15: I like to plan ahead in detail rather than leaving things to chance

HTQ 16: Being taken by surprise makes me uncomfortable

HTQ 19: I like movies or stories with definite endings

HTQ 20: Even after I have reached a decision, I continue to think about the pros and cons in order to make sure that I did not make a mistake R

HTQ 21: I would much rather socialize with people I know than with people I've not met before

HTQ 22: I like being able to organize everything in advance

HTQ 23: I struggle to make decisions about minor things such as how to dress and what to order in a restaurant $\mathrm{R}$

HTQ 24: I dislike it when a person says something that could have many different meanings

3) Belief - beliefs about the value of having routines or habits (not about the personal self but general)

HTQ 13: Traditions are important to me

HTQ 25: Rituals are important even if they are not enjoyable

HTQ 27: A good job has clear guidelines on what to do and how to do it

HTQ 28: A person who leads a regular, predictable life is lucky

HTQ 26: Life is boring if you never take risks and always play it safe $\mathrm{R}$ 
HTQ 9: There is comfort in regularity

HTQ 29: The best group meetings have definite agendas

4) Thinking style - compulsive thinking style (susceptibility to habitual or non-goal directed behaviour)

HTQ 31: I have difficulty thinking clearly in new and unfamiliar situations

HTQ 32: It does not bother me to leave a task unfinished $R$

HTQ 33: I tend to repeat actions because I keep doubting that I have done them properly

HTQ 34: I feel that there are certain actions I have to do to prevent something bad from happening

HTQ 35: The same thoughts often keep going through my mind over and over again

HTQ 36: I mentally fixate on certain issues and can't move on

HTQ 37: I tend to dwell on the same issues 


\section{Exploratory factor analysis (Study 1)}

Table S1. First exploratory factor analysis of original 37-item Habitual Tendencies Questionnaire.

\begin{tabular}{|c|c|c|c|c|c|}
\hline \multirow{2}{*}{ Items } & \multicolumn{4}{|c|}{ Component Loadings } & \multirow[b]{2}{*}{ Uniqueness } \\
\hline & Factor 1 & Factor 2 & Factor 3 & Factor 4 & \\
\hline HTQ 36: I mentally fixate on certain issues and can't move on & 0.92 & -0.02 & -0.03 & 0.01 & 0.820 \\
\hline HTQ 37: I tend to dwell on the same issues & 0.90 & -0.07 & 0.04 & 0.01 & 0.772 \\
\hline HTQ 35: The same thoughts often keep going through my mind over and over again & 0.86 & -0.09 & 0.08 & 0.06 & 0.710 \\
\hline HTQ 31: I have difficulty thinking clearly in new and unfamiliar situations & 0.58 & 0.30 & 0.15 & -0.22 & 0.637 \\
\hline HTQ 33: I tend to repeat actions because I keep doubting that I have done them properly & 0.54 & 0.18 & -0.2 & -0.22 & 0.457 \\
\hline HTQ 1: I hate it when my routines are disrupted & 0.08 & 0.68 & 0.15 & -0.02 & 0.575 \\
\hline HTQ 22: I like being able to organize everything in advance & 0.08 & 0.67 & -0.25 & 0.34 & 0.659 \\
\hline HTQ 6: I tend to stick with technology that I am familiar with for as long as I can & -0.17 & 0.66 & 0.05 & -0.08 & 0.394 \\
\hline HTQ 9: There is comfort in regularity & -0.19 & 0.65 & 0.01 & 0.05 & 0.399 \\
\hline HTQ 10: I like to have a regular, unchanging schedule & -0.09 & 0.63 & 0.16 & -0.02 & 0.442 \\
\hline HTQ 27: A good job has clear guidelines on what to do and how to do it & -0.10 & 0.63 & -0.02 & 0.09 & 0.388 \\
\hline HTQ 16: Being taken by surprise makes me uncomfortable & 0.07 & 0.62 & 0.18 & 0.14 & 0.562 \\
\hline HTQ 4: I feel anxious when things change frequently & 0.22 & 0.59 & 0.23 & -0.14 & 0.604 \\
\hline HTQ 24: I dislike it when a person says something that could have many different meanings & 0.12 & 0.59 & -0.04 & -0.1 & 0.380 \\
\hline HTQ 18: I tend to do things in the same order every morning & 0.05 & 0.56 & 0.01 & 0.00 & 0.334 \\
\hline HTQ 19: I like movies or stories with definite endings & 0.02 & 0.53 & 0.03 & 0.03 & 0.304 \\
\hline HTQ 14: I like tasks that require very little thought once I've learned them & 0.08 & 0.48 & -0.09 & -0.34 & 0.306 \\
\hline HTQ 3: I avoid situations where unexpected things might happen & -0.02 & 0.47 & 0.32 & 0.08 & 0.421 \\
\hline HTQ 28: A person who leads a regular, predictable life is lucky & 0.19 & 0.46 & 0.27 & -0.13 & 0.441 \\
\hline HTQ 29: The best group meetings have definite agendas & 0.11 & 0.44 & -0.11 & 0.36 & 0.404 \\
\hline HTQ 8: It greatly bothers me when someone picks up one of my belongings and does not put it back exactly in its original place & 0.11 & 0.41 & -0.08 & 0.04 & 0.202 \\
\hline HTQ 30: I look forward to new experiences R & 0.09 & 0.05 & 0.85 & -0.01 & 0.760 \\
\hline HTQ 26: Life is boring if you never take risks and always play it safe $\mathrm{R}$ & -0.02 & 0.03 & 0.64 & 0.11 & 0.444 \\
\hline HTQ 7: When eating at restaurants, I like to try new dishes rather than ones I have tried before $\mathrm{R}$ & 0.00 & 0.03 & 0.54 & 0.07 & 0.311 \\
\hline HTQ 5: I like being spontaneous R & 0.04 & 0.32 & 0.46 & 0.45 & 0.665 \\
\hline HTQ 2: I tend to change my plans last minute $\mathrm{R}$ & -0.08 & 0.15 & 0.18 & 0.66 & 0.559 \\
\hline HTQ 23: I struggle to make decisions about minor things such as how to dress and what to order in a restaurant & 0.38 & 0.19 & -0.06 & -0.53 & 0.515 \\
\hline HTQ 15: I like to plan ahead in detail rather than leaving things to chance & 0.09 & 0.43 & -0.17 & 0.47 & 0.485 \\
\hline HTQ 20: Even after I have reached a decision, I continue to think about the pros and cons in order to make sure that I did not make a mistake & 0.37 & 0.25 & -0.37 & 0.19 & 0.363 \\
\hline HTQ 11: Vacations often cause me stress & 0.30 & 0.16 & 0.25 & -0.20 & 0.28 \\
\hline HTQ 21: I would much rather socialize with people I know than with people I've not met before & 0.29 & 0.24 & 0.07 & 0.26 & 0.272 \\
\hline HTQ 17: I always go on vacation to the same destination & 0.22 & 0.2 & 0.10 & -0.33 & 0.242 \\
\hline HTQ 34: I feel that there are certain actions I have to do to prevent something bad from happening & 0.39 & 0.12 & -0.22 & -0.06 & 0.223 \\
\hline HTQ 13: Traditions are important to me & -0.30 & 0.3 & 0.04 & -0.36 & 0.188 \\
\hline HTQ 12: I'd rather understand why things turned out a certain way than just let them happen & 0.10 & 0.19 & -0.21 & 0.27 & 0.163 \\
\hline HTQ 32: It does not bother me to leave a task unfinished R & 0.06 & 0.15 & 0.18 & 0.24 & 0.152 \\
\hline HTQ 25: Rituals are important even if they are not enjoyable & -0.12 & 0.27 & -0.04 & -0.20 & 0.078 \\
\hline Correlation with Factor 1 & 1.00 & & & & \\
\hline Correlation with Factor 2 & 0.32 & 1.00 & & & \\
\hline Correlation with Factor 3 & 0.07 & 0.25 & 1.00 & & \\
\hline Correlation with Factor 4 & -0.13 & 0.20 & 0.03 & 1.00 & \\
\hline
\end{tabular}


Table S2. Second exploratory factor analysis of Habitual Tendencies Questionnaire after exclusion criteria applied - 20 items.

\begin{tabular}{|c|c|c|c|c|}
\hline \multirow{2}{*}{ Items } & \multicolumn{3}{|c|}{ Component Loadings } & \multirow[b]{2}{*}{ Uniqueness } \\
\hline & Factor 1 & Factor 2 & Factor 3 & \\
\hline HTQ 37: I tend to dwell on the same issues & 0.91 & -0.03 & 0.01 & 0.18 \\
\hline HTQ 36: I mentally fixate on certain issues and can't move on & 0.88 & 0.02 & -0.03 & 0.22 \\
\hline HTQ 35: The same thoughts often keep going through my mind over and over again & 0.84 & -0.01 & 0.06 & 0.28 \\
\hline HTQ 33: I tend to repeat actions because I keep doubting that I have done them properly & 0.59 & 0.11 & -0.18 & 0.62 \\
\hline HTQ 1: I hate it when my routines are disrupted & 0.08 & 0.73 & 0.06 & 0.40 \\
\hline HTQ 9: There is comfort in regularity & -0.17 & 0.71 & -0.08 & 0.56 \\
\hline HTQ 27: A good job has clear guidelines on what to do and how to do it & -0.08 & 0.70 & -0.12 & 0.58 \\
\hline HTQ 10: I like to have a regular, unchanging schedule & -0.08 & 0.68 & 0.09 & 0.51 \\
\hline HTQ 16: Being taken by surprise makes me uncomfortable & 0.04 & 0.66 & 0.11 & 0.48 \\
\hline HTQ 6: I tend to stick with technology that I am familiar with for as long as I can & -0.11 & 0.61 & 0.00 & 0.65 \\
\hline HTQ 4: I feel anxious when things change frequently & 0.25 & 0.60 & 0.10 & 0.44 \\
\hline HTQ 24: I dislike it when a person says something that could have many different meanings & 0.15 & 0.54 & -0.09 & 0.68 \\
\hline HTQ 19: I like movies or stories with definite endings & 0.03 & 0.53 & 0.01 & 0.70 \\
\hline HTQ 18: I tend to do things in the same order every morning & 0.08 & 0.53 & -0.01 & 0.69 \\
\hline HTQ 28: A person who leads a regular, predictable life is lucky & 0.22 & 0.50 & 0.20 & 0.52 \\
\hline HTQ 8: It greatly bothers me when someone picks up one of my belongings and does not put it back exactly in its original place & 0.10 & 0.40 & -0.05 & 0.83 \\
\hline HTQ 30: I look forward to new experiences R & 0.02 & 0.01 & 0.92 & 0.13 \\
\hline HTQ 26: Life is boring if you never take risks and always play it safe $R$ & -0.07 & 0.01 & 0.67 & 0.56 \\
\hline HTQ 7: When eating at restaurants, I like to try new dishes rather than ones I have tried before $\mathrm{R}$ & -0.06 & 0.04 & 0.52 & 0.72 \\
\hline HTQ 2: I tend to change my plans last minute $R$ & -0.21 & 0.33 & 0.12 & 0.85 \\
\hline Correlation with Factor 1 & 1.00 & & & \\
\hline Correlation with Factor 2 & 0.25 & 1.00 & & \\
\hline Correlation with Factor 3 & 0.15 & 0.37 & 1.00 & \\
\hline
\end{tabular}

$\mathrm{R}=$ reversed item 

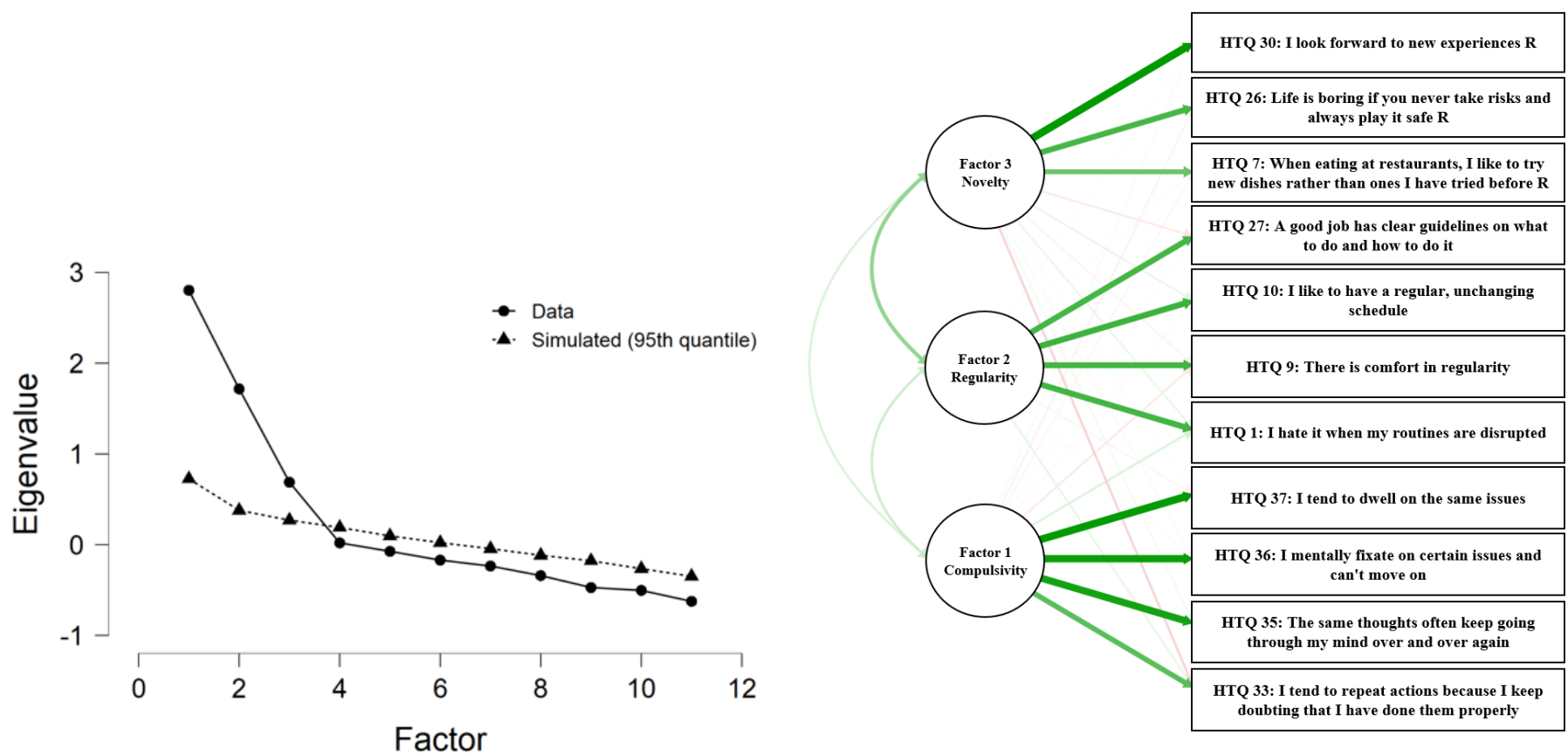

Figure S1. Scree plot and path plot of exploratory factor analysis of final 11-item Habitual Tendencies Questionnaire (HTQ).

\section{Confirmatory factor analysis (Study 2 and combined sample)}

Table S3. Confirmatory factor analysis of 11-item Habitual Tendencies Questionnaire (HTQ), Study 2.

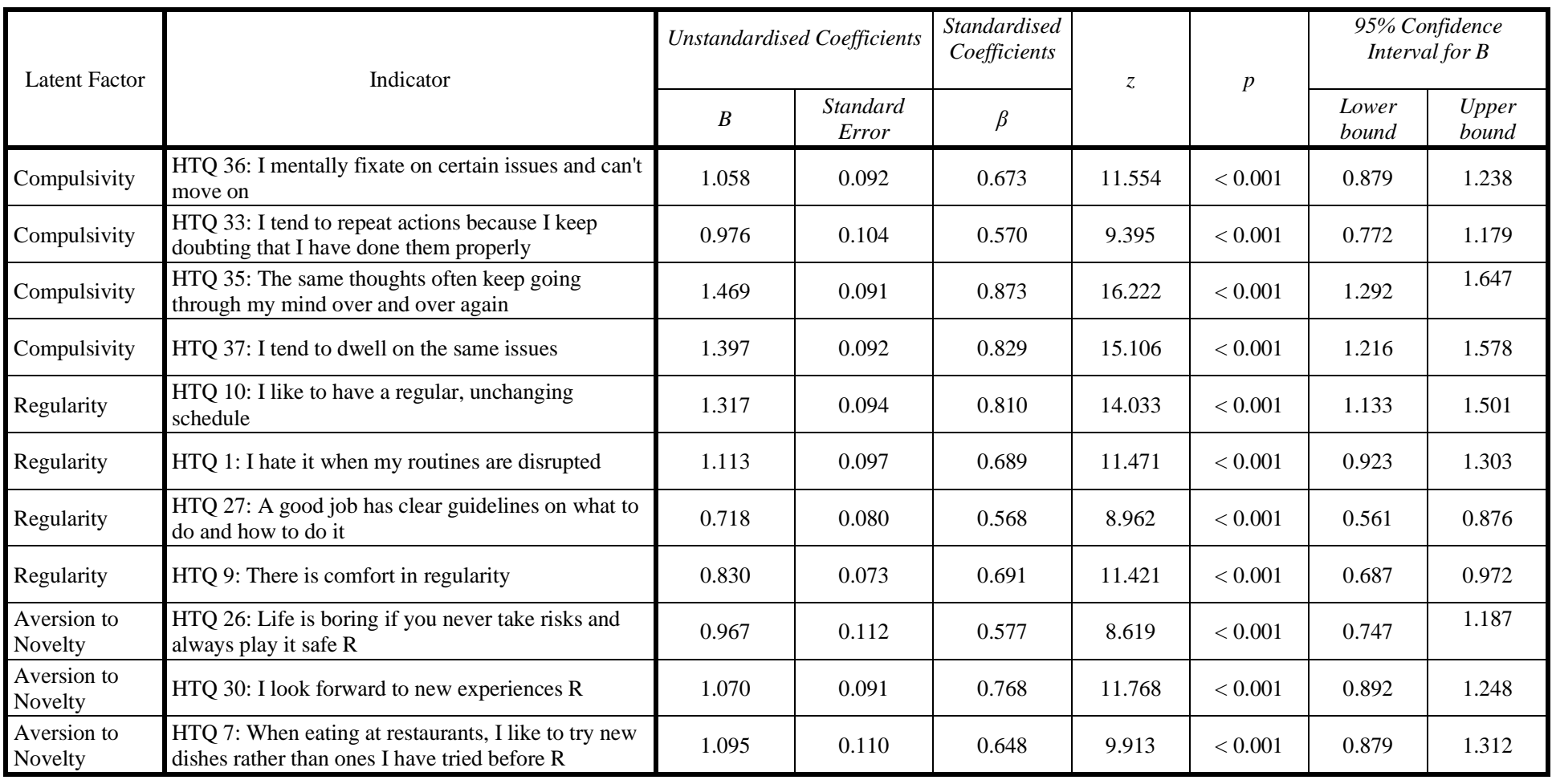




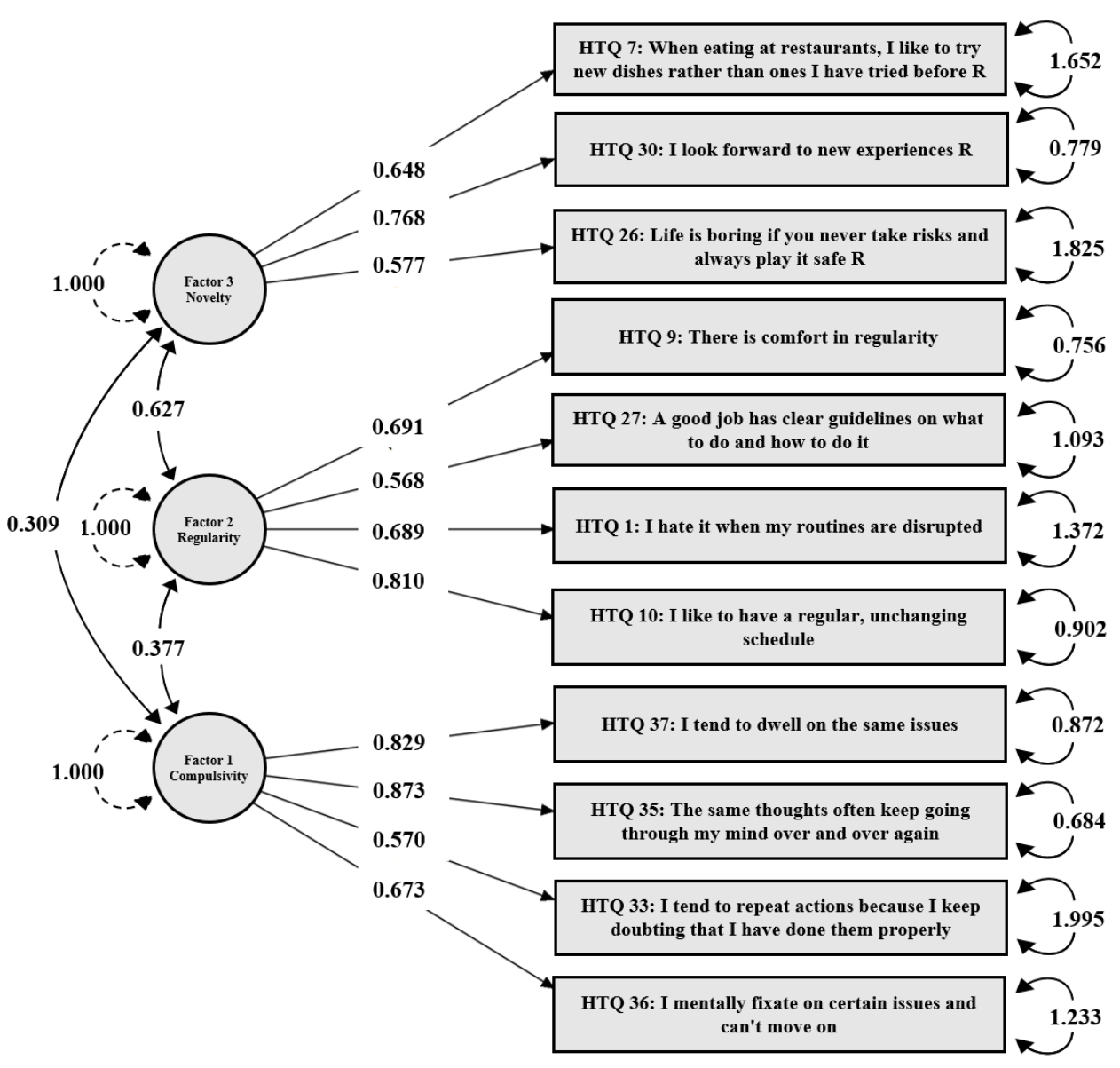

Figure S2. Path plot of confirmatory factor analysis of final 11-item Habitual Tendencies Questionnaire (HTQ). 
Table S4. Confirmatory factor analysis of 11-item Habitual Tendencies Questionnaire (HTQ), Study $1+2$ combined analysis.

\begin{tabular}{|c|c|c|c|c|c|c|c|c|}
\hline \multirow{2}{*}{ Latent Factor } & \multirow{2}{*}{ Indicator } & \multicolumn{2}{|c|}{ Unstandardised Coefficients } & \multirow{2}{*}{$\begin{array}{c}\begin{array}{c}\text { Standardised } \\
\text { Coefficients }\end{array} \\
\beta\end{array}$} & \multirow{2}{*}{$z$} & \multirow{2}{*}{$p$} & \multicolumn{2}{|c|}{$\begin{array}{l}95 \% \text { Confidence } \\
\text { Interval for } B\end{array}$} \\
\hline & & $B$ & $\begin{array}{l}\text { Standard } \\
\text { Error }\end{array}$ & & & & $\begin{array}{l}\text { Lower } \\
\text { bound }\end{array}$ & $\begin{array}{l}\text { Upper } \\
\text { bound }\end{array}$ \\
\hline Compulsivity & $\begin{array}{l}\text { HTQ 36: I mentally fixate on certain issues and can't } \\
\text { move on }\end{array}$ & 1.204 & 0.075 & 0.735 & 16.049 & $<0.001$ & 1.057 & 1.351 \\
\hline Compulsivity & $\begin{array}{l}\text { HTQ 33: I tend to repeat actions because I keep } \\
\text { doubting that I have done them properly }\end{array}$ & 0.952 & 0.083 & 0.562 & 11.413 & $<0.001$ & 0.788 & 1.115 \\
\hline Compulsivity & $\begin{array}{l}\text { HTQ 35: The same thoughts often keep going } \\
\text { through my mind over and over again }\end{array}$ & 1.465 & 0.073 & 0.869 & 20.164 & $<0.001$ & 1.322 & 1.607 \\
\hline Compulsivity & HTQ 37: I tend to dwell on the same issues & 1.448 & 0.073 & 0.857 & 19.782 & $<0.001$ & 1.305 & 1.592 \\
\hline Regularity & $\begin{array}{l}\text { HTQ 10: I like to have a regular, unchanging } \\
\text { schedule }\end{array}$ & 1.241 & 0.075 & 0.791 & 16.450 & $<0.001$ & 1.093 & 1.389 \\
\hline Regularity & HTQ 1: I hate it when my routines are disrupted & 1.115 & 0.078 & 0.705 & 14.257 & $<0.001$ & 0.962 & 1.268 \\
\hline Regularity & $\begin{array}{l}\text { HTQ 27: A good job has clear guidelines on what to } \\
\text { do and how to do it }\end{array}$ & 0.713 & 0.064 & 0.577 & 11.059 & $<0.001$ & 0.587 & 0.840 \\
\hline Regularity & HTQ 9: There is comfort in regularity & 0.780 & 0.059 & 0.670 & 13.314 & $<0.001$ & 0.665 & 0.895 \\
\hline $\begin{array}{l}\text { Aversion to } \\
\text { Novelty }\end{array}$ & $\begin{array}{l}\text { HTQ 26: Life is boring if you never take risks and } \\
\text { always play it safe R }\end{array}$ & 1.014 & 0.091 & 0.604 & 11.197 & $<0.001$ & 0.837 & 1.192 \\
\hline $\begin{array}{l}\text { Aversion to } \\
\text { Novelty }\end{array}$ & HTQ 30: I look forward to new experiences R & 1.119 & 0.074 & 0.812 & 15.092 & $<0.001$ & 0.973 & 1.264 \\
\hline $\begin{array}{l}\text { Aversion to } \\
\text { Novelty }\end{array}$ & $\begin{array}{l}\text { HTQ 7: When eating at restaurants, I like to try new } \\
\text { dishes rather than ones I have tried before R }\end{array}$ & 1.007 & 0.088 & 0.614 & 11.493 & $<0.001$ & 0.835 & 1.178 \\
\hline
\end{tabular}




\section{Additional analyses}

Relationships between the Habitual Tendencies Questionnaire (HTQ) and the Intolerance of Uncertainty Scale, IUS (Carleton et al., 2007)

The HTQ showed a strong positive correlation with the IUS $(r=0.728, p<0.001)$, and most notably, there was a strong positive correlation between the Regularity subscale of the HTQ and the Prospective Anxiety subscale of the IUS $(r=0.649, p<0.001)$, suggesting that these tap into similar constructs, as expected. The Pearson's $r$ effect sizes of 0.728 and 0.649 are relatively large, as per the individual differences research guidelines set out by Gignac and Szodorai (2016).

To complement the Pearson's correlations, we also examined the Bayes Factors (see Table S5), which quantify the evidential strength in favour of a significant correlation given the present data $\left(\mathrm{H}_{1}\right.$, the alternative hypothesis), or in favour of no significant correlation given the present data $\left(\mathrm{H}_{0}\right.$, the null hypothesis). In line with the guidelines by Wagenmakers and colleagues (2018), a Bayes Factor $\left(\mathrm{BF}_{10}\right)$ above 100 indicates "extreme evidence" for $\mathrm{H}_{1}$ (significant correlation). Here we found that the relationship between HTQ Regularity and the Prospective Anxiety subscale of the IUS demonstrated an extremely large Bayes Factor of $1.001 \times 10^{14}$, indicating that the observed data is $1.001 \times 10^{14}$ times more likely under $\mathrm{H}_{1}$ than $\mathrm{H}_{0}$.

Relationships between the HTQ and the Autism Quotient, AQ (Allison et al., 2012)

There was a significant positive correlation between the HTQ and the AQ ( $r=0.418, p$ $<0.001$ ), with the Compulsivity subscale of the HTQ contributing the most to this association $(r=0.423, p<0.001)$. The Pearson's $r$ effect sizes of 0.418 and 0.423 are relatively large, (Gignac and Szodorai, 2016). Examination of the Bayes Factors (see Table S5), revealed that the relationship between HTQ Compulsivity and the AQ demonstrated an extremely large 
Bayes Factor of 26840.001, indicating that the observed data is 26840.001 times more likely under $\mathrm{H}_{1}$ (significant correlation) than $\mathrm{H}_{0}$ (no correlation). As this Bayes Factor value is above 100 , it indicates "extreme evidence" for $\mathrm{H}_{1}$, in line with the guidelines from Wagenmakers and colleagues (2018).

Table S5. Correlation matrix of the Habitual Tendencies Questionnaire, Intolerance of Uncertainty Scale and Autism Quotient, including Pearson's correlations and Bayes Factors, for additional analyses, Study 1.

\begin{tabular}{|c|c|c|c|c|c|c|c|c|}
\hline & & HTQ & $\begin{array}{c}\text { HTQ } \\
\text { Compulsivit } \\
\mathrm{y}\end{array}$ & $\begin{array}{c}\text { HTQ } \\
\text { Regularity }\end{array}$ & $\begin{array}{c}\text { HTQ } \\
\text { Aversion to } \\
\text { Novelty }\end{array}$ & IUS & $\begin{array}{c}\text { IUS } \\
\text { Prospective } \\
\text { Anxiety }\end{array}$ & $\begin{array}{c}\text { IUS } \\
\text { Inhibitory } \\
\text { Anxiety }\end{array}$ \\
\hline \multirow[t]{2}{*}{ HTQ } & $\begin{array}{l}\text { Pearson's } \\
\mathrm{r}\end{array}$ & - & & & & & & \\
\hline & $\mathrm{BF}_{10}$ & - & & & & & & \\
\hline \multirow{2}{*}{$\begin{array}{l}\text { HTQ } \\
\text { Compulsivit } \\
\text { y }\end{array}$} & $\begin{array}{l}\text { Pearson's } \\
\mathrm{r}\end{array}$ & $0.728 * * *$ & - & & & & & \\
\hline & $\mathrm{BF}_{10}$ & $4.897 \times 10^{19}$ & - & & & & & \\
\hline \multirow[t]{2}{*}{$\begin{array}{l}\text { HTQ } \\
\text { Regularity }\end{array}$} & $\begin{array}{l}\text { Pearson's } \\
\mathrm{r}\end{array}$ & $0.672 * * *$ & 0.161 & - & & & & \\
\hline & $\mathrm{BF}_{10}$ & $2.863 \times 10^{15}$ & 0.573 & - & & & & \\
\hline \multirow{2}{*}{$\begin{array}{l}\text { HTQ } \\
\text { Aversion to } \\
\text { Novelty }\end{array}$} & $\begin{array}{l}\text { Pearson's } \\
\mathrm{r}\end{array}$ & $0.577 * * *$ & 0.065 & $0.278 * *$ & - & & & \\
\hline & $\mathrm{BF}_{10}$ & $1.335 \times 10^{10}$ & 0.143 & 17.309 & - & & & \\
\hline \multirow[t]{2}{*}{ IUS } & $\begin{array}{l}\text { Pearson's } \\
\mathrm{r}\end{array}$ & $0.728 * * *$ & $0.519 * * *$ & $0.608 * * *$ & $0.303 * * *$ & - & & \\
\hline & $\mathrm{BF}_{10}$ & $4.829 \times 10^{19}$ & $4.385 \times 10^{7}$ & $4.720 \times 10^{11}$ & 47.049 & - & & \\
\hline \multirow{2}{*}{$\begin{array}{l}\text { IUS } \\
\text { Prospective } \\
\text { Anxiety }\end{array}$} & $\begin{array}{l}\text { Pearson's } \\
\mathrm{r}\end{array}$ & $0.696 * * * *$ & $0.467 * * *$ & $0.649 * * *$ & $0.260 * *$ & $0.960 * * *$ & - & \\
\hline & $\mathrm{BF}_{10}$ & $1.588 \times 10^{17}$ & 609825.233 & $1.001 \times 10^{14}$ & 9.117 & $3.706 \times 10^{68}$ & - & \\
\hline \multirow{2}{*}{$\begin{array}{l}\text { IUS } \\
\text { Inhibitory } \\
\text { Anxiety }\end{array}$} & $\begin{array}{l}\text { Pearson's } \\
\mathrm{r}\end{array}$ & $0.677 * * *$ & $0.523 * * *$ & $0.476 * * *$ & $0.321 * * *$ & $0.926 * * *$ & $\mathbf{0 . 7 8 4} * * *$ & - \\
\hline & $\mathrm{BF}_{10}$ & $6.709 \times 10^{15}$ & $6.002 \times 10^{7}$ & $1.164 \times 10^{6}$ & 105.201 & $3.429 \times 10^{52}$ & $1.247 \times 10^{25}$ & - \\
\hline \multirow[t]{2}{*}{$\mathrm{AQ}$} & $\begin{array}{l}\text { Pearson's } \\
\mathrm{r}\end{array}$ & $0.418 * * *$ & $0.423 * * *$ & 0.111 & $0.249 * *$ & $0.432 * * *$ & $0.394 * * *$ & $0.428 * * *$ \\
\hline & $\mathrm{BF}_{10}$ & 19778.737 & 26840.001 & 0.238 & 6.289 & 49673.888 & 4482.546 & 38854.172 \\
\hline $\begin{array}{l}* p<0.05, * \\
\text { Very strong } \\
\text { HTQ }=\text { Habi }\end{array}$ & $\begin{array}{l}\text { ence; } 0.01, * * \\
\text { Tendenci }\end{array}$ & $\begin{array}{l}\quad 0.001 ; \mathrm{BF} \\
=\text { Extremel } \\
\text { uestionnaire }\end{array}$ & $\begin{array}{l}=\text { Anecdotal } \\
\text { trong eviden } \\
\text { US = Intoler }\end{array}$ & $\begin{array}{l}\text { nce; } B F \\
\text { f Uncert }\end{array}$ & $\begin{array}{l}\text { Moderate } \\
\text { Scale. AQ }\end{array}$ & $\begin{array}{l}\text { nce; } B F<33 \\
\text { tism Quoti }\end{array}$ & rong evide & $\mathrm{F}<100=$ \\
\hline
\end{tabular}

